\title{
FLA14 is required for pollen development and preventing premature pollen germination under high humidity in Arabidopsis
}

Yingjing Miao ${ }^{1,2}$, Jiashu Cao², Li Huang ${ }^{2}$, Youjian Yu³ and Sue Lin ${ }^{1,4^{*}}$

\begin{abstract}
Background: As an important subfamily of arabinogalactan proteins (AGPs), fasciclin-like AGPS (FLAs) contribute to various aspects of growth, development and adaptation, yet their function remains largely elusive. Despite the diversity of FLAs, only two members, Arabidopsis FLA3 and rice MTR1, are reported to be involved in sexual reproduction. In this study, another Arabidopsis FLA-encoding gene, FLA14, was identified, and its role was investigated.

Results: Arabidopsis FLA14 was found to be a pollen grain-specific gene. Expression results from fusion with green fluorescent protein showed that FLA14 was localized along the cell membrane and in Hechtian strands. A loss-offunction mutant of FLA14 showed no discernible defects during male gametogenesis, but precocious pollen germination occurred inside the mature anthers under high moisture conditions. Overexpression of FLA14 caused 39.2\% abnormal pollen grains with a shrunken and withered appearance, leading to largely reduced fertility with short mature siliques and lower seed set. Cytological and ultramicroscopic observation showed that ectopic expression of FLA14 caused disruption at the uninucleate stage, resulting in either collapsed pollen with absent intine or pollen of normal appearance but with a thickened intine.
\end{abstract}

Conclusions: Taken together, our data suggest a role for FLA14 in pollen development and preventing premature pollen germination inside the anthers under high relative humidity in Arabidopsis.

Keywords: Arabidopsis, Fasciclin-like arabinogalactan proteins, Microspore development, Intine formation, Pollen germination, High humidity

\section{Background}

In flowering plants, pollen acts as a biological protector of male sperm and is responsible for delivering twin sperm cells via the pollen tube to the embryo sac for double fertilization [1]. Angiosperm pollen ontogenesis is composed of two sequential phases: a developmental phase leading to the formation of mature pollen grains and a functional phase [2]. Male gametophyte development occurs within the anther locules of the stamen. It

\footnotetext{
${ }^{*}$ Correspondence: iamkari@163.com

${ }^{1}$ Institute of Life Sciences, College of Life and Environmental Science,

Wenzhou University, Wenzhou 325000, China

Full list of author information is available at the end of the article
}

is a complex process that is initiated by microsporocytes that undergo meiosis to thereby form tetrads of haploid microspores, and it ends with the release of mature pollen grains at the anthesis stage [2,3]. After the tetrad stage, the precise construction of a multilayered pollen wall controlled by the microspore itself and the sporophytic tapetum is a major event in pollen development [4, 5]. The fundamental structure of the pollen wall is highly similar across species and comprises an inner pectocellulosic intine layer and an outer sporopollenin-based exine layer filled with tryphine (pollen coat) [5]. Exine, whose major component is sporopollenin, is composed of inner nexine and outer sexine that form a three-dimensional structure composed of baculae and a roof-like tectum $[6$, 
7]. The intine layer is the last layer of the pollen wall, consisting of hydrolytic enzymes, hydrophobic proteins, cellulose, hemicellulose, and pectic polymers [5]. Successful male gametophyte development requires coordinated activities of different gametophytic and sporophytic cells and involves widespread appropriate expression of specific genes [8]. The functional phase of pollen ontogenesis begins with the activation of pollen grains by rehydration on the stigma surface, followed by germination and explosive pollen tube growth, and ends with the accomplishment of double fertilization [9]. In Arabidopsis, the progression pattern of proliferating microspores to terminally differentiated pollen is quite clear [10], and tremendous efforts involving genetic and transcriptomic approaches have led to the isolation of several key components related to this unique process, helping to unravel the regulatory mechanism of male gametogenesis, pollen germination, and pollen tube growth $[1,2,5,11,12]$.

Arabinogalactan proteins (AGPs) are highly glycosylated glycoproteins, that each comprise an O-glycosylated core protein backbone and arabinogalactan polysaccharide chains mainly consisting of galactan and arabinose $[13,14]$. AGPs are ubiquitous in all plant tissues and cells and are particularly abundant in the cell wall, plasma membrane, apoplastic space and extracellular matrix [15]. The complexity arising from the incredible diversity of glycans decorating the protein backbone makes AGPs a large complex family in higher plants. To date, a total of 85 and 282 putative AGPs have been identified in the Arabidopsis genome and the Oryza sativa genome, respectively $[16,17]$. Previous studies have demonstrated that AGPs are extensively implicated in diverse plant growth and development processes under different conditions, such as sexual reproduction (microspore development, female gametogenesis, embryo development, pollen-pistil interaction, pollen germination, and pollen tube growth), vegetative growth (stem development, vascular tissue function, and root development), programmed cell death, cell division and expansion, and response to abiotic stress [13, 15, 18-27].

AGPs are divided into seven subfamilies based on differences in the domain constituents of their core protein backbone sequences: classical AGPs, lysine-rich AGPs, AG peptides, fasciclin-like AGPs (FLAs), nodulin-like AGPs, xylogen-like AGPs, and nonclassical AGPs [13, 22, 28]. FLAs are distinguished from other AGP subfamilies because they contain one or two fasciclin domains (the FAS domain), which may function in cell communication and adhesion (physical interaction) [29-31]. Specifically, the FAS domains are composed of 110-150 amino acids and have low sequence similarity, they contain a conserved central $\mathrm{YH}$ motif and two highly conserved regions ( $\mathrm{H} 1$ and $\mathrm{H} 2)$, and each region comprises 10 amino acids [30, 32, 33]. Many different putative FLAs have been identified throughout higher plants. For example, 21 FLAs have been identified in Arabidopsis, 27 in $O$. sativa, and 34 in Triticum aestivum [30, 31, 34]. Arabidopsis FLAs are divided into four groups (A-D) based on the number and location of FAS and AGP-like domains and the presence or absence of glycosyl phosphatidylinositol (GPI) anchor signals [30]. However, functional investigation of FLAs has been challenged by the redundancy of members, resulting in many fla mutants having no discernible phenotypes. At present, the effects of FLAs have been associated with the formation of plant secondary cell walls and wood, shoot and root development, cell adhesion, and responses to abiotic stresses [32]. In addition, the study of FLA3 in Arabidopsis and MTR1 in rice revealed the involvement of FLAs in plant reproductive development, especially in pollen formation $[35,36]$. However, despite the diversity of FLAs, knowledge of the biological functions of FLAs and of their molecular mechanisms in plants remains elusive.

In this study, a pollen-specific FLA gene, FLA14, was isolated and characterized. The loss-of-function mutant of FLA14 showed no discernible phenotype under standard growth conditions, but premature ectopic pollen germination occurred inside the anthers under high moisture conditions, suggesting an essential role of FLA14 in maintaining the proper timing of pollen germination. FLA14-overexpressing transgenic plants were found to produce approximately $39.2 \%$ collapsed and shrunken pollen grains, which displayed decreased pollen germination and pollen tube growth. Cytological observations and electron microscopy revealed that pollen abortion occurred at the uninucleate stage, and aberrant pollen grains lost all cytoplasmic materials, nuclei, and intine, with abnormal distribution of cellulose-like polysaccharides seen by calcofluor white staining, whereas the basic structure of the exine layer and tryphine was normal. These results strongly indicated that ectopic expression of FLA14 may affect microspore development, especially pollen intine formation.

\section{Results}

\section{Characterization of FLA14}

All 21 FLA protein sequences were obtained from the Arabidopsis Information Resource (TAIR) [30]. Using aligned full-length FLA sequences, an unrooted phylogenetic tree showing their phylogenetic relationships was constructed (Additional file 1: Fig. S1a). Based on phylogenetic analysis and pairwise sequence comparison, FLA14 (AT3G12660), which was identified in the annotated Arabidopsis genome, belongs to group $\mathrm{C}$ of the FLA subfamily (Additional file 1: Fig. S1a), which 
is consistent with previous results [30]. According to the gene expression data obtained from the Arabidopsis eFP Browser and previous transcriptome data of male gametophytes and seedlings in Arabidopsis $[37,38], F L A 14$ is a pollen-specific gene that is especially highly expressed in immature tricellular pollen (Additional file 1: Fig. S1b-d). It has a 768-bp-long open reading frame (ORF) with no intron, encoding a 255-amino-acid protein that is rich in Pro (5.9\%), Ala (9.0\%), Ser (14.5\%) and Thr (6.3\%) (Additional file 2: Fig. S2a). FLA14 contains only one FAS domain (117 amino acids long) as a key distinguishing feature and has two relatively conserved regions $(\mathrm{H} 1$ and $\mathrm{H} 2)(10$ and 11 amino acids long, respectively) at either end of the domain (Additional file 2: Fig. S2). In addition, this protein includes an $\mathrm{N}$-terminal secretion signal peptide with a cleavage site between the amino acids at positions 21 (Ser) and 22 (Asn) predicted by SignalP 4.0 Server, TMHMM Server v. 2.0 and SMART, and a potential GPI modification site at amino acid position 225 (Ser) predicted by GPI-SOM and BIG-PI Plant Predictor (Additional file 2: Fig. S2b).

\section{FLA14 is specifically expressed in pollen grains}

To follow the temporal and spatial expression of FLA14, quantitative real-time PCR was first performed in different tissues. The results showed that FLA14 expression was specifically abundant in flowers but barely detectable in mature roots, stems, leaves or germinal siliques (Fig. 1a). Arabidopsis expressing the GUS reporter gene and $e G F P$ gene driven by the FLA14 promoter (proFLA14::eGFP-GUS) were constructed and analyzed. According to the stage definition described by Smyth et al. [39], the GUS signal was first detected in anthers at floral stage 11 and rapidly reached a high level in intact anther tissue at floral stage 12 (Fig. 1b). The expanded blue signal in pollen sacs and other floral organs could be the result of the reaction products of GUS enzyme activity diffusing from pollen grains, as the eGFP fluorescent signal in the anthers was only confined to pollen grains, as petals were colorless when stained separately (Fig. 1e, g, h). At floral stage 12 and the anthesis stage, the GUS signal was not only seen in pollen grains but also obvious in the stigma and transmitting tract (Fig. 1b-d).

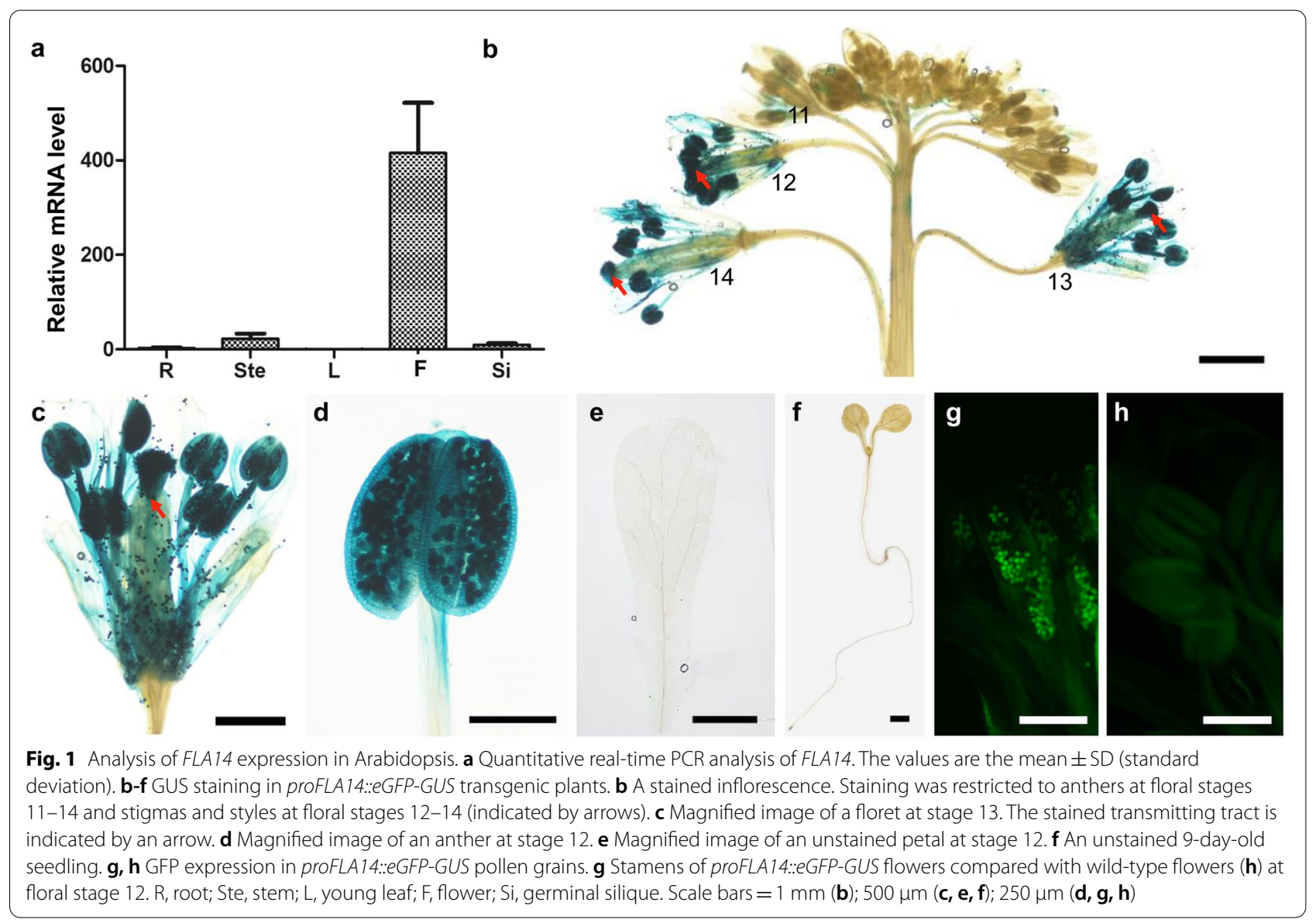


GUS activity was not detected in any other nonreproductive tissues (Fig. 1e, f), which was consistent with the quantitative real-time PCR results. The specific expression pattern of FLA14 in pollen grains strongly suggested its potential involvement in pollen development and function.

\section{FLA14 is localized along the plasma membrane and in Hechtian strands}

To investigate the subcellular localization of FLA14, an eGFP gene was fused to FLA14 to form an $e G F P-F L A 14$ construct under the control of the constitutive CaMV $35 \mathrm{~S}$ promoter. To avoid potential disturbance of the signal peptide of the FLA14 backbone, eGFP was inserted into FLA14 at the signal peptide cleavage site between the amino acids at positions 21 (Ser) and 22 (Asn). Afterward, this construct was transiently transformed into onion epidermal cells. Our results showed that the fluorescent signal of FLA14 fused with eGFP appeared as a spotty cytoplasmic pattern and displayed broad distribution along the cell boundaries, which was observed on the plasma membrane and in intercellular spaces and Hechtian strands (a stretched plasma membrane extending from the plasmolyzed protoplast to the cell wall in plants) of plasmolyzed cells (Fig. 2e-1), while the fluorescent signal was restricted inside the cell membrane in control cells transformed with a $p F G C$-eGFP empty vector (Fig. 2a-d). These results indicated that FLA14 is a plasma membranebound protein.

\section{Generation of FLA14 loss-of-function mutant} and overexpressing transgenic plants

To study the biological function of FLA14, two mutants (CS1014037 and SALK_123695) harboring T-DNA insertions, one in the coding region of FLA14 699 bp downstream of the initiation codon (ATG) and the other located 945 bp upstream of the FLA14 mRNA initiation site, were identified (Fig. 3a). Additionally, we generated FLA14 overexpression (OE) transgenic plants (Fig. 3b). The homozygous CS1014037 mutant fla14-1, homozygous SALK_123695 mutant fla14-2 and 14 OE-positive transformants were verified by genomic DNA PCR (Additional file 3: Fig. S3). In the quantitative real-time PCR results, weak or almost no FLA14 mRNA could be detected in the whole inflorescences of fla14-1 and fla142 (Fig. 3c), with three specific primer pairs (Additional file 4: Table S1 and Fig. 3a), indicating that transcription of the FLA14 gene was strongly suppressed by T-DNA insertion. Moreover, compared with wild-type (WT) inflorescences, significantly enhanced FLA14 transcript levels in the inflorescences from $13 \mathrm{OE}$ lines were confirmed (Fig. 3d).

\section{Mutation in FLA14 results in precocious pollen germination inside the anthers under high moisture conditions}

The loss-of-function mutants of FLA14, fla14-1 and fla14-2 displayed consistent plant growth and reproductive development phenotypes. In addition, we observed that under standard growth conditions, there were no obvious morphological differences between fla14 (Fig. 4b) and WT plants (Fig. 4a). The opening

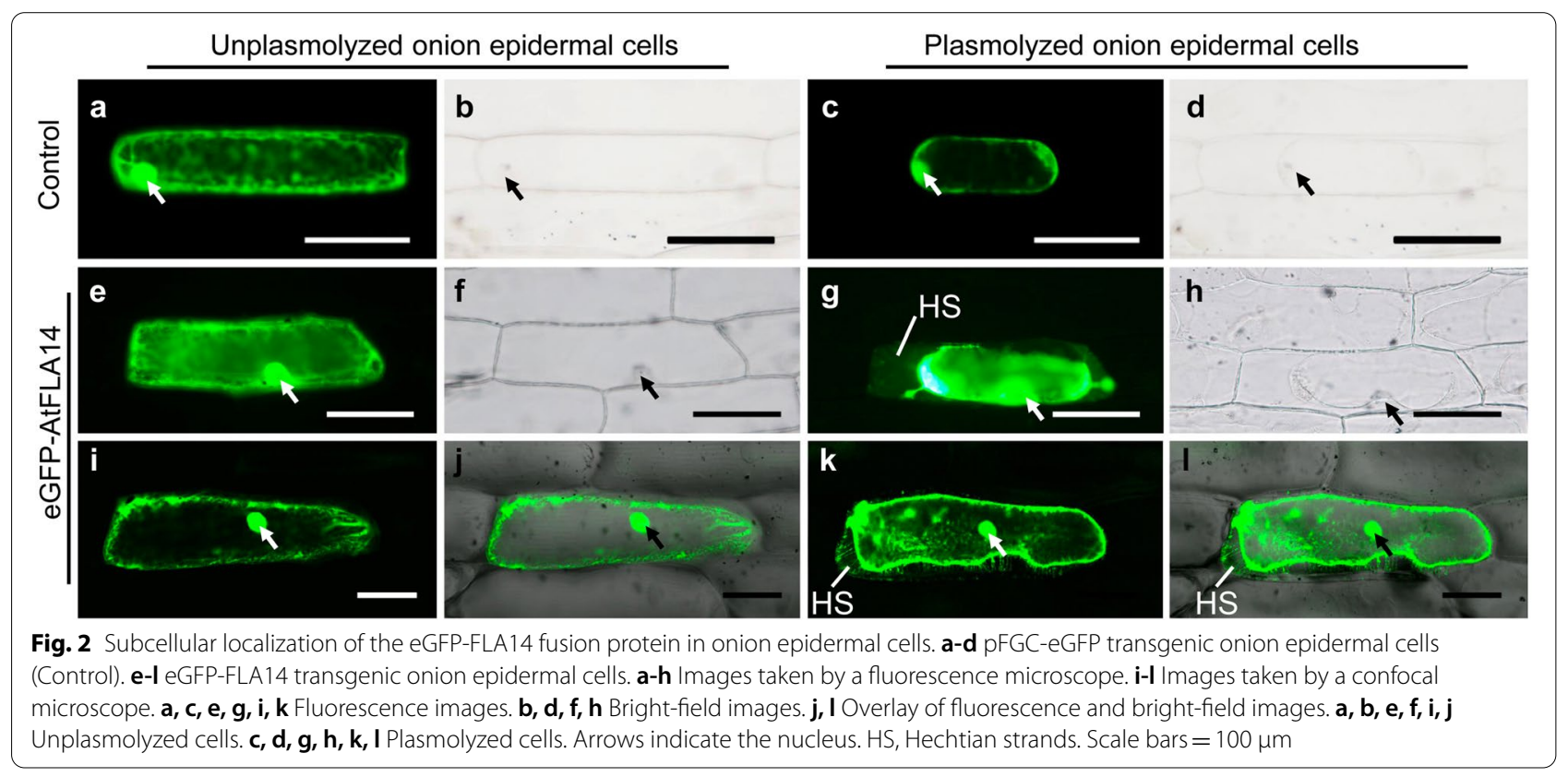




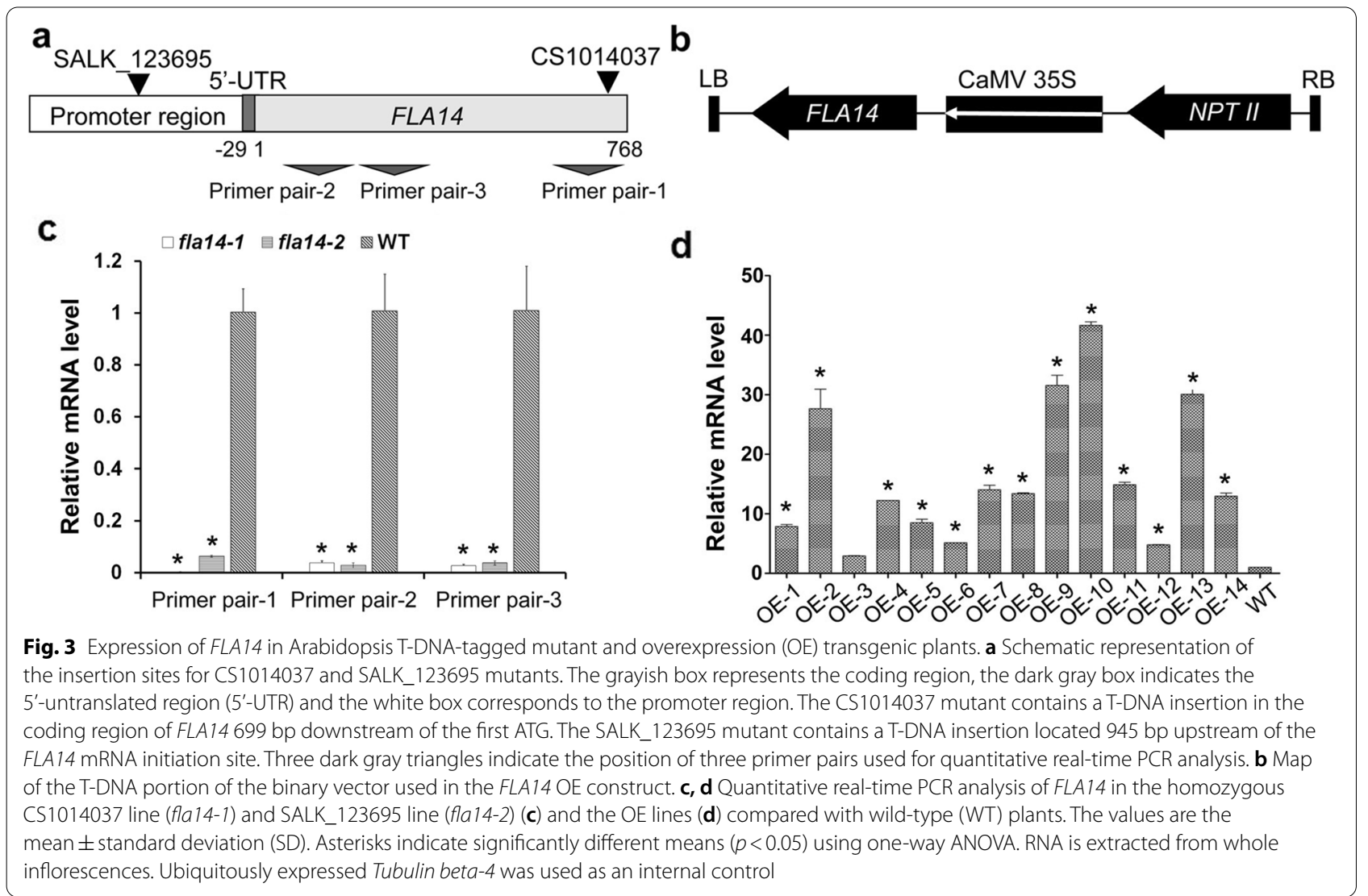

florets of fla14 had a normal appearance, with yellow and plump anthers (Fig. 4e, h), similar to WT florets (Fig. 4d, g), and mature siliques showed no reduction in length or seed set (Fig. 4k, n). Normal-appearing pollen grains with precisely positioned germinal apertures were observed in the anthers of fla14 (Fig. 5f, g), which were similar to WT pollen grains (Fig. 5a, b). Cytological observations revealed that fla14 pollen grains displayed normal pollen viability, nuclear distribution, and deposition of cellulose-like polysaccharides (Fig. $5 \mathrm{~h}-\mathrm{j}$, r, s). In vivo self and reciprocal crosses between fla14 and WT plants further confirmed that neither the male nor female gametophytes of fla14 were impaired (Additional file 5: Fig. S4).

However, it is worth noting that pollen germination and elongation were determined to be altered when fla14 was transferred to high moisture conditions with a relative air humidity of $85 \%$. In fla14, a considerable number of highly elongated pollen tubes were consistently observed inside the anthers at $85 \%$ humidity (Fig. 6e-h). In contrast, precocious germination of pollen tubes was never observed in the anthers of WT plants under either controlled (50\%) (Fig. 5f-h) or high (85\%) (Fig. 6a-d) relative humidity conditions.

\section{FLA14 overexpression in transgenic plants causes} microspore abortion at the uninucleate stage OE plants without any apparent vegetative defects showed severe sterility compared with WT plants (Fig. 4j, l, m, o). We randomly selected three OE lines (5, 9, and 11) with markedly enhanced FLA14 transcript levels for further analysis. The mature siliques of OE plants $(8.66 \pm 1.26 \mathrm{~mm})$ were obviously shorter than those of WT plants $(15.11 \pm 0.92 \mathrm{~mm})$ (Fig. 4p), producing much fewer seeds (23.9 \pm 13.5 per silique) than WT plants $(60.9 \pm 4.4$ per silique) (Fig. 4q). OE plants displayed a partial male-sterile phenotype with approximately $39.2 \%$ distorted pollen grains (Fig. $5 \mathrm{k}, \mathrm{l}, \mathrm{v}$ ), while only a $5.5 \%$ pollen abortion frequency was observed in WT plants (Fig. 5a, b, v). Cytological observations revealed that these collapsed pollen grains from the opening flowers were unviable and lacked cell content and nuclei, and the deposition of cellulose-like polysaccharides seemed to be aberrant when traced by calcofluor white staining (Fig. 5m-o, t, u).

Further analysis of pollen tube behavior via self and reciprocal crosses was also conducted using aniline blue to trace callose. When WT pollen was employed as the male donor, comparison of OE (Fig. $7 \mathrm{~m}-\mathrm{o}, \mathrm{s}-\mathrm{u}$ ) and 

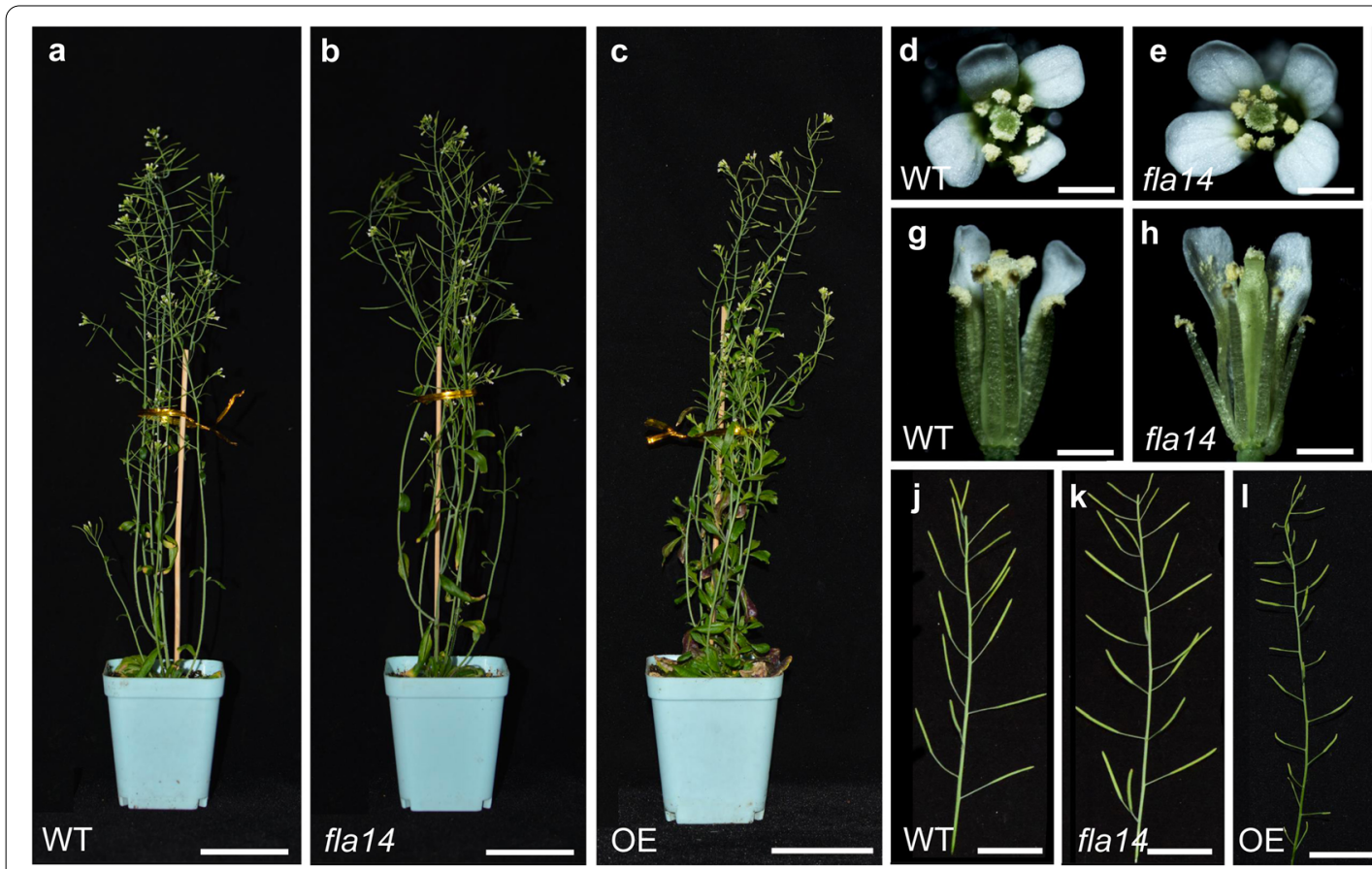

flater
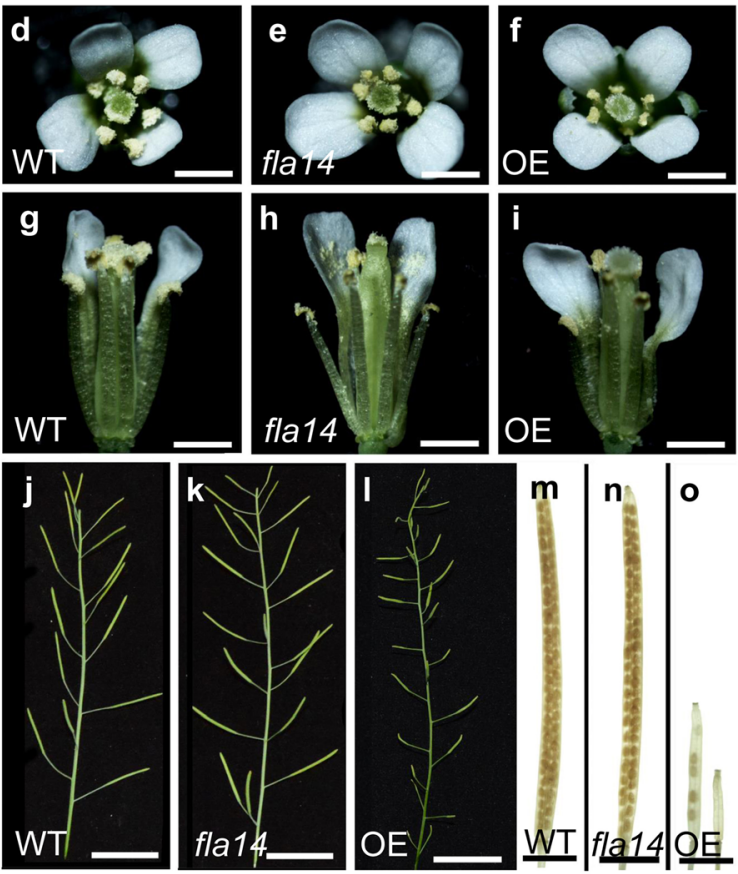

p
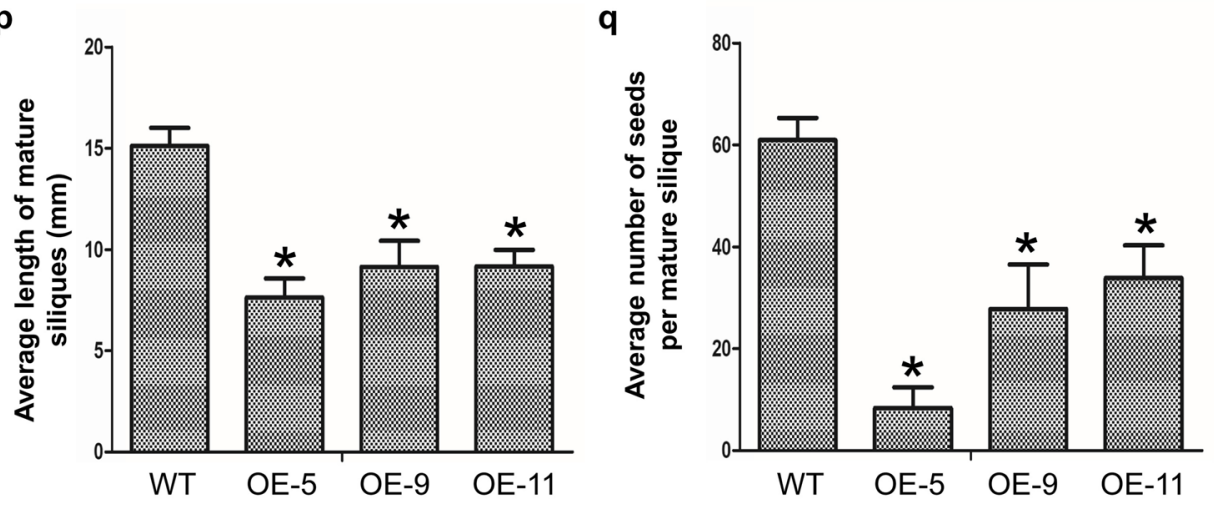

Fig. 4 Fertility analysis of FLA14 knockout mutant (fla14) and overexpression (OE) transgenic Arabidopsis plants. a-c Morphological observation of wild-type (WT) (a), fla 14 (b), and OE (c) plants. d-i A WT floret (d, g), a fla14 floret (e, h), and an OE floret (f, i). $\mathbf{j}-\mathbf{I}$ Comparison of silique development in WT (j), fla14 (k), and OE (I) plants. The OE siliques were smaller than the normal siliques of fla14 and WT plants. $\mathbf{m}$-o Ethanol-fixed siliques of WT ( $\mathbf{m})$, fla 14 (n), and OE (o) plants. The OE siliques show few mature ovules. p Length of mature siliques in WT and OE plants. The values are the mean \pm standard deviation (SD). Asterisks indicate significantly different means $(p<0.01)$ using one-way ANOVA. q Number of seeds per silique in WT and OE plants. The values are the mean \pm standard SD. Asterisks indicate significantly different means $(p<0.01)$ using one-way ANOVA. Scale bars $=5 \mathrm{~cm}(\mathbf{a}-\mathbf{c}) ; 1 \mathrm{~mm}(\mathbf{d}-\mathbf{i}) ; 2 \mathrm{~cm}(\mathbf{j}-\mathbf{l}) ; 5 \mathrm{~mm}(\mathbf{m}-\mathbf{o})$

WT (Fig. 7a-c, g-i) pistils failed to reveal differences in pollen tube behavior. However, when pollen from the OE plants was employed as the male donor, the amount of pollen tubes in OE (Fig. 7p-r, v-x) and WT (Fig. 7d-f, $\mathrm{j}-\mathrm{l}$ ) pistils was obviously lower than that of WT pollen tubes in both OE (Fig. 7m-o, s-u) and WT (Fig. 7a-c, g-i) pistils, although the pollen tube behavior in $\mathrm{OE}$ and WT pistils was similar. Therefore, aniline blue staining analysis demonstrated that the male gametophytes of OE plants were impaired.
To investigate the precise stage during which pollen collapse started due to the enhanced FLA14 transcript levels, floral buds from the OE plants were fixed, embedded and sectioned for analysis of anther development. The sporophytic tapetum of $\mathrm{OE}$ anthers appeared normal, were fully developed by the tetrad stage, and gradually degenerated during the late stage of the microspore development process (Fig. 8f-j), with no obvious distinction compared with the tapetum of WT anthers (Fig. 8a-e). However, the maturation process of 


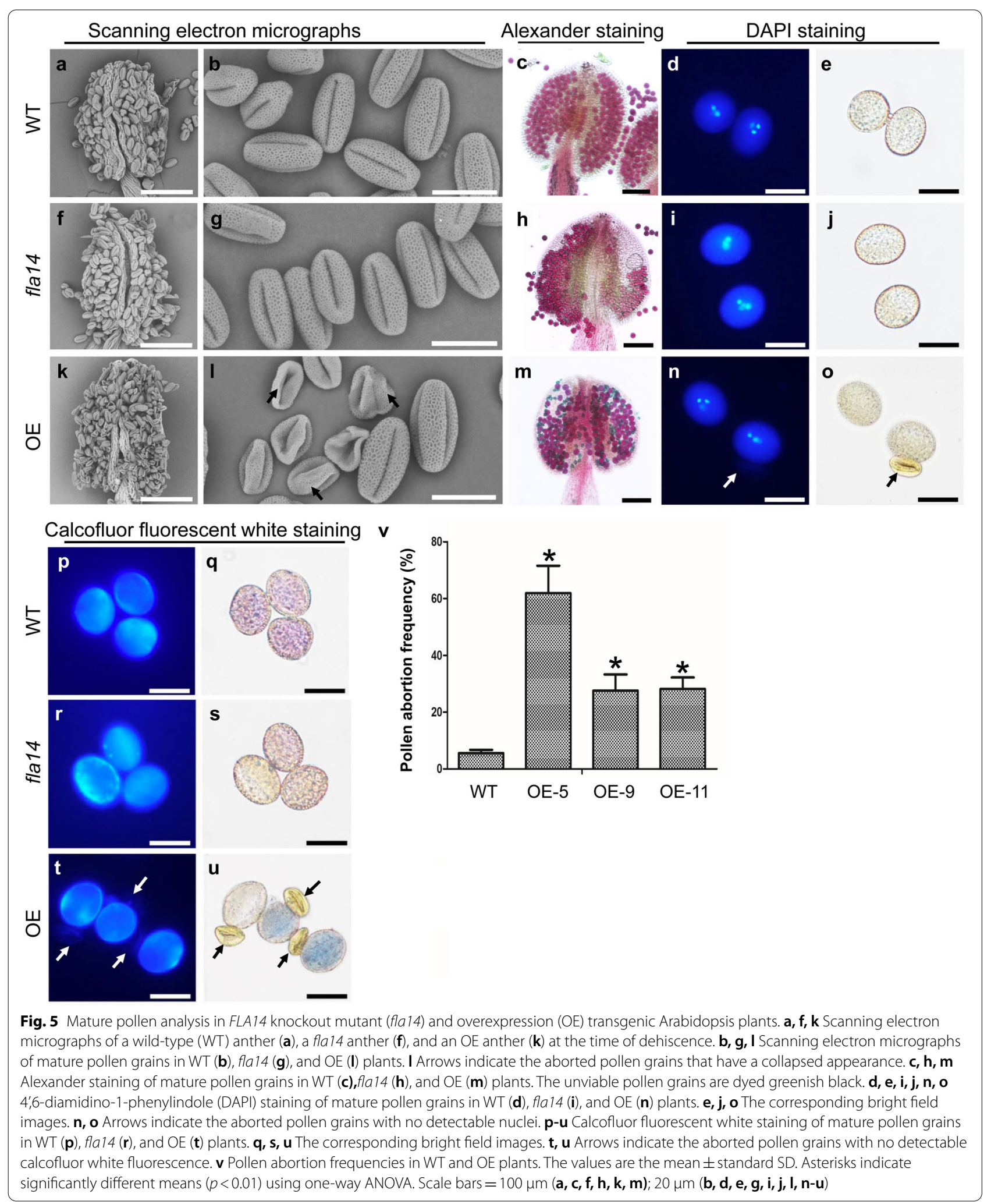




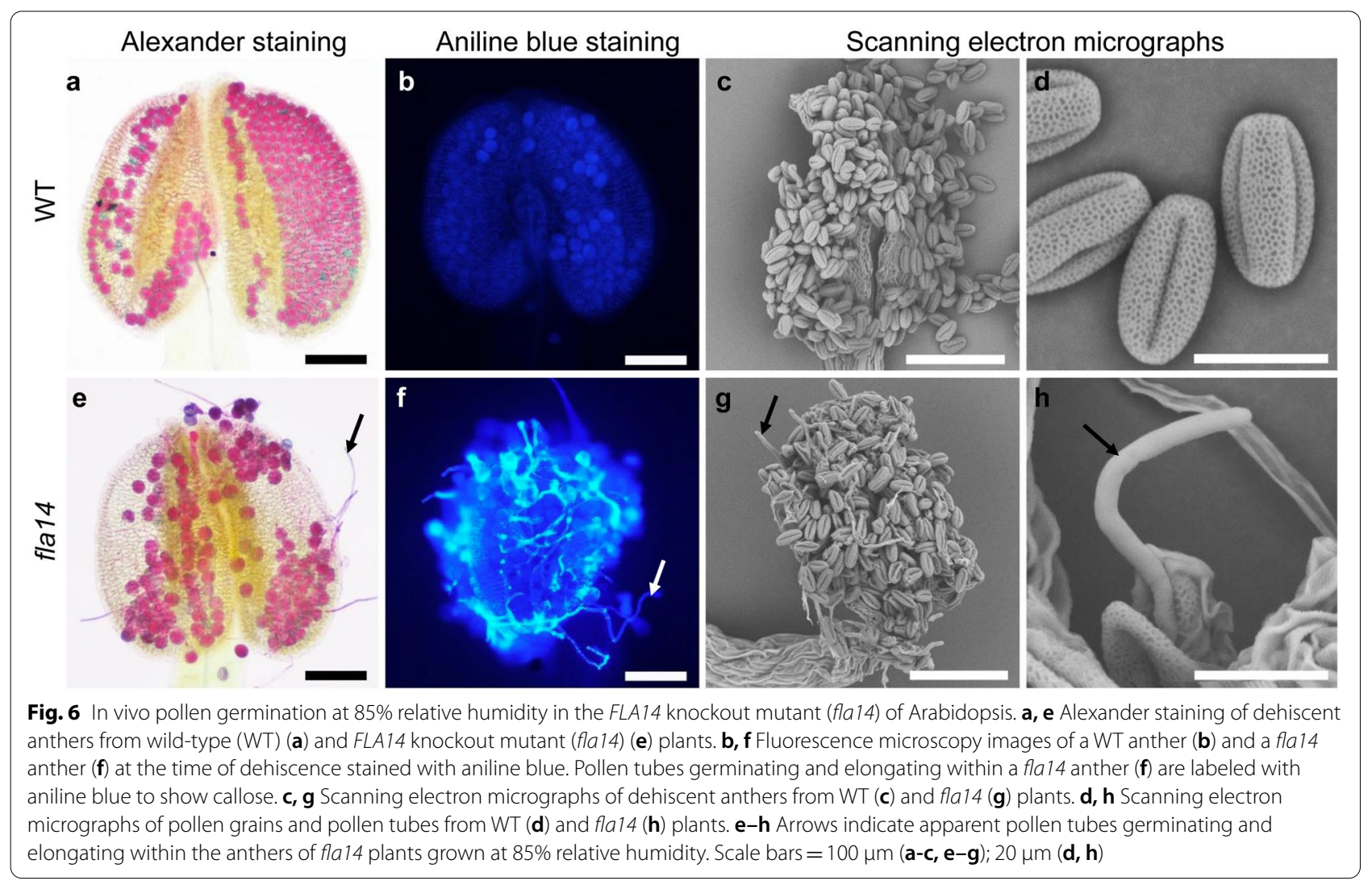

OE pollen grains prior to anther dehiscence was distinguished since the uninucleate stage (Fig. 8h). A total of 27.6-61.9\% bicellular microspores of OE plants were accompanied by extensive degeneration of all cytoplasmic contents (Fig. 8i) and formed remnants at the dehiscent stage (Fig. 8j). Therefore, semithin section analysis demonstrated that only the microspore development process was impaired in OE plants, with no defects in tapetum formation and degradation.

Abnormalities of $\mathrm{OE}$ microspores and their pollen wall structure, which was gradually constructed during pollen development, were further confirmed by TEM. Most aberrant pollen grains in OE plants showed a collapsed appearance (Fig. 9q), in contrast with the roughly round pollen grains of WT plants (Fig. 9g). From the microspore mother cell stage to the tetrad stage, all the developing cells in the OE anther locules (Fig. 9i, j) exhibited the same morphology and pollen wall patterning as those of WT plants (Fig. 9a, b). The young microspores surrounded by the callose wall at the tetrad stage showed the initiation of exine wall formation. However, degradation of the cytoplasm was evident at the uninucleate stage (Fig. 9k), which was different from observations of individual haploid WT microspores (Fig. 9c). Moreover, the intine layer of $\mathrm{OE}$ microspores was unable to form at this point (Fig. 9l) compared with the presence of almost complete basic intine and exine structures in WT microspores (Fig. 9d). Subsequently, the degradation of the cytoplasmic content and the failure of intine formation led to the fading of nuclei and the collapse of bicellular microspores (Fig. 9m). By the dehiscent stage, the $\mathrm{OE}$ anthers released empty and shrunken pollen grains that were completely devoid of cell contents and an intine layer but with an intact exine layer and a well-developed tryphine (Fig. 9q, r). In addition, some sporadic cases of aberrant pollen grains with a normal appearance but remarkable thickening of the intine layer were observed inside the $\mathrm{OE}$ pollen sac (Fig. 9o, s). This kind of pollen grain underwent similar development to WT pollen grains before the uninucleate stage. However, dramatic overdeposition of the intine layer became apparent starting from the bicellular stage (Fig. 9p, $\mathrm{t})$. All these results indicated that microspore abortion in OE plants occurred at the uninucleate stage and suggested a role of FLA14 in microspore development and pollen wall patterning in Arabidopsis, especially in intine formation.

\section{The deposition of cellulose-like polysaccharides during pollen wall formation is impaired in FLA14-overexpressing transgenic plants}

To determine how FLA14 affects intine formation, we used calcofluor white staining to trace the deposition 
of cellulose-like polysaccharides during the formation of the pollen wall in OE plants. Very faint calcofluor white fluorescence was first detected in OE (Fig. 10j, o) and WT microspores (Fig. 10a, f) at the early uninucleate stage and rapidly formed obvious fluorescent spots at the late uninucleate stage (Fig. 10b, g, k, p). In WT microspores, the intine displayed a distinct fluorescent ring outside the cytoplasm at the bicellular and tricellular stages (Fig. 10c, d, h, i). However, some small and aborted pollen grains with no detectable calcofluor white fluorescent signals were found in OE plants at the bicellular and tricellular stages (Fig. 10l, m, q, r). In addition, pollen grains that were normal in shape but that had enhanced calcofluor white fluorescence signals were also observed at a very low proportion in OE plants (Fig. 10e, n, s). This phenomenon of unusual enhancement of fluorescence signals has never been observed in WT pollen grains. The correlation between the abnormal distribution of calcofluor white fluorescence (no fluorescence or a significantly enhanced fluorescent signal) and the aberrant intine patterning (failed to form or markedly thickened) reflected in TEM (Fig. 9) suggested that ectopic expression of FLA14 may affect Arabidopsis pollen intine formation probably through disturbing the deposition of cellulose-like polysaccharides.

\section{Discussion}

Ectopic expression of FLA14 leads to impaired microspores with defective pollen intine formation

In recent years, a set of investigations have identified a batch of AGPs with specific expression and function in male reproductive tissues, demonstrating the undoubtedly important role of AGPs in pollen ontogenesis [20, $34,35,40-42]$. However, to our knowledge, there are currently only two FLAs, Arabidopsis FLA3 and rice MTR1, that are reported to be endowed with a specific role in microspore development $[35,36]$. In this study, we identified a FLA-encoding gene, FLA14, which displayed a strict pollen-specific expression pattern (Fig. 1). To study the function of FLA14, mutants harboring T-DNA insertions and CaMV $35 \mathrm{~S}$ promoter-driven FLA14-OE transgenic Arabidopsis plants were generated. The activity of the CaMV $35 \mathrm{~S}$ promoter in Arabidopsis pollen has always been controversial. However, the CaMV $35 \mathrm{~S}$ promoter is still widely used in the functional analysis of pollen-expressed genes. Taking AGP family members as an example, CaMV $35 \mathrm{~S}$ promoter-driven RNAi plants in Arabidopsis were generated to study the function of AGP6 and AGP11, both of which were found to be specifically expressed in stamens, pollen grains and pollen tubes [41, 43]. Downregulation of FLA3, which is specifically expressed in pollen grains and tubes, caused pollen abnormalities in CaMV $35 \mathrm{~S}$ promoter-driven RNAi plants [35]. Overexpression of FLA3 under the CaMV $35 \mathrm{~S}$ promoter also led to marked sterility [35]. Additionally, transgenic plants of Brassica campestris expressing antisense $B c M F 8$ and/or $B c M F 18$, which are specifically expressed in pollen grains and/or pollen tubes, under the control of the CaMV $35 \mathrm{~S}$ promoter showed partial male sterility and decreased seed set [42, 44]. In our study, analysis of fla14 mutants and FLA14-overexpressing transgenic Arabidopsis plants controlled by the CaMV $35 \mathrm{~S}$ promoter was performed.

The data presented here indicated that membranebound FLA14 is associated with the proper progression of pollen development (Fig. 2, 5). Although early results from fla14 null-mutant characterization showed no alteration in plant phenotype under standard growth conditions (Fig. 4, 5), the effects of FLA14 overexpression were evident as early as the uninucleate stage during the microspore development process (Fig. 8, 9). Notably, the initiation and timing of exine formation in OE plants was normal and similar to that in WT plants (Fig. 9). However, unlike in WT plants, intine in OE plants did not form properly and was followed by the degeneration of microspore cytoplasm. Moreover, in accordance with the intine defects, our calcofluor white staining results showed an absence or excess of fluorescence signals in the aborted pollen grains of OE plants, which demonstrated abnormal distribution of cellulose-like polysaccharides in the pollen grains (Fig. 10). All these results suggested that ectopic expression of FLA14 is likely to disturb the distribution of cellulose-like polysaccharides in developing pollen cells.

Thus, the question arises of how ectopic expression of FLA14 affects the distribution of cellulose-like polysaccharides in OE pollen. As the innermost layer surrounding the microspores, intine is composed of multiple components (cellulose, hemicellulose, pectin, hydrolytic enzymes and structural proteins) that are covalently and noncovalently linked [45]. Protein glycosylation is a

(See figure on next page.)

Fig. 7 Self and reciprocal crosses between wild-type (WT) and FLA14-overexpressing (OE) transgenic Arabidopsis plants. a-c WT pollen tubes in WT pistils at $4 \mathrm{~h}$ after pollination (HAP), $12 \mathrm{HAP}$, and $24 \mathrm{HAP}$, respectively. d-f Pollen tubes of OE plants in WT pistils at $4 \mathrm{HAP}, 12 \mathrm{HAP}$, and $24 \mathrm{HAP}$, respectively. $\mathbf{m}-\mathbf{o}$ WT pollen tubes in OE pistils at $4 \mathrm{HAP}, 12 \mathrm{HAP}$, and $24 \mathrm{HAP}$, respectively. p-r Pollen tubes of OE plants in OE pistils at $4 \mathrm{HAP}$, 12 HAP, and 24 HAP, respectively. $\mathbf{g}-\mathbf{I}$ and $\mathbf{s}-\mathbf{x}$ The corresponding magnified images of (a-f) and (m-r). Scale bars $=200 \mu \mathrm{m}$ 


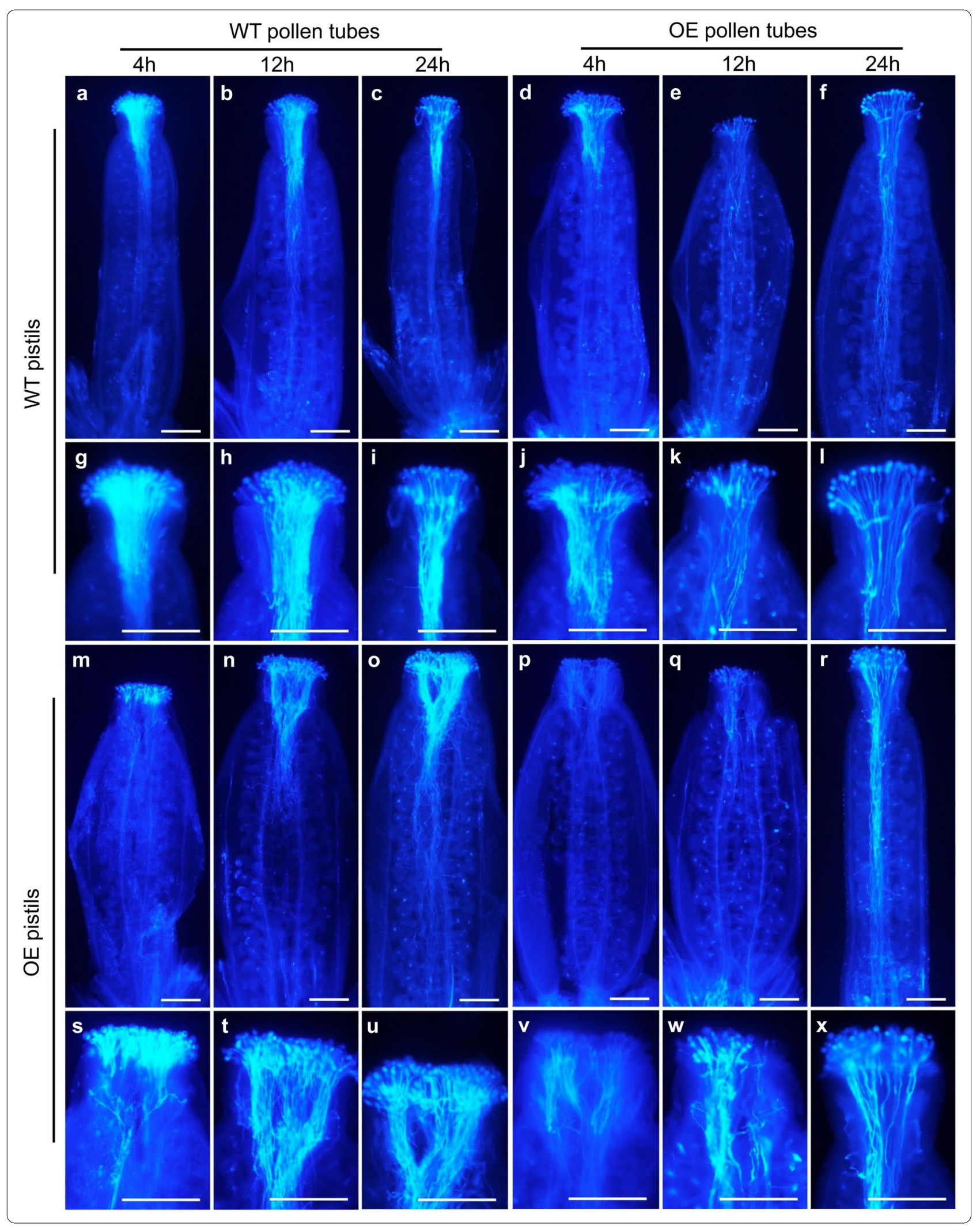




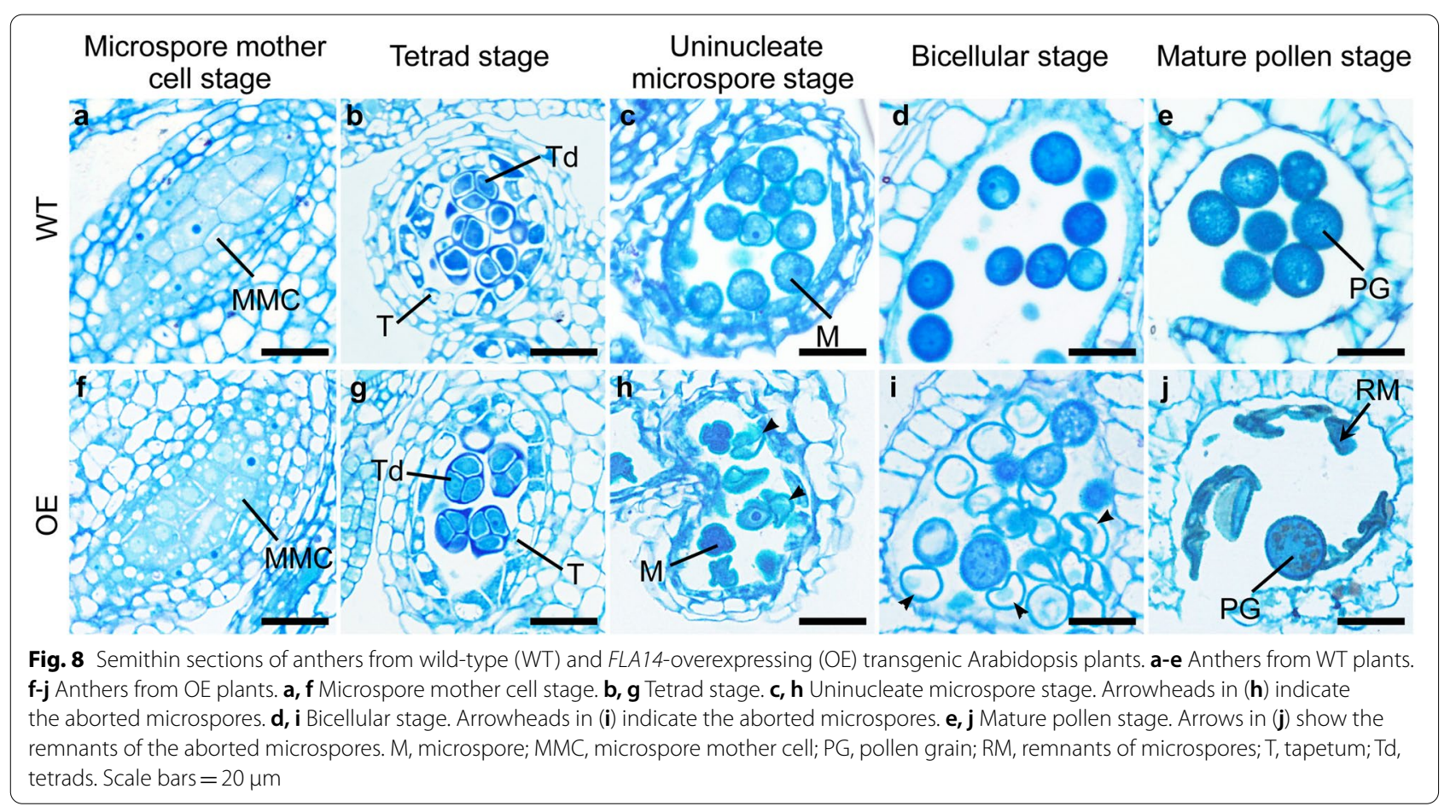

cotranslational or posttranslational covalent attachment of carbohydrate chains to the polypeptide backbone, which is an essential modification for proper protein structure and function in the male gametophyte [46]. Proteoglycans are important components of the pollen wall, among which AGPs are a prominent family of highly glycosylated glycoproteins [13]. Nevertheless, the assembly of AGPs within the pollen wall system and the connection with other extracellular matrix components are poorly understood. Previous studies have demonstrated that AGPs may serve as covalent cross-linkers and plasticizers in the cell wall and form linkages with other components of the cell wall, mainly pectin and arabinoxylan [47, 48]. This continuous proteoglycan structure network in consequently influences extracellular matrix integrity and helps to maintain cell expansion [48, 49]. For instance, an Arabidopsis AGP (AGP57C) was proposed to covalently interact with pectins and hemicelluloses. In addition, BcMF18 in B. campestris was suggested to be an integral part of pollen intine formation, possibly as a cross-linker in the formation of proteoglycan structure [50]. Hence, we hypothesize that periplasm-AGPs are good candidates for the proteoglycan structure in pollen intine and may help to maintain intine integrity, providing a safe interior environment for microspore development. Therefore, overexpression of FLA14 disorders the homeostatic level of proteoglycan during microspore expansion, resulting in changes in structural components and abnormal intine construction (Fig. 9). Subsequently, abnormal intine construction further affects the pollen internal environment and leads to the degradation of the cytoplasmic content in OE pollen grains (Fig. 9), as the intine layer is considered to play an important role in pollen stability and integrity $[35,50,51]$.

\section{FLA14 is essential for preventing premature pollen germination inside anthers under high relative humidity in Arabidopsis}

The presence of AGPs within pollen tubes has been documented in diverse plant species, mainly at their apex $[27,52,53]$. A specific subset of AGPs was shown to be

\section{(See figure on next page.)}

Fig. 9 Transmission electron micrographs of microspores from wild-type (WT) and FLA14-overexpressing (OE) transgenic Arabidopsis plants. a-h Microspores from WT plants. $\mathbf{i}-\mathbf{t}$ Microspores from OE plants. $\mathbf{a}$, i Microspore mother cell stage. $\mathbf{b}, \mathbf{j}$ Tetrad stage. $\mathbf{c}, \mathbf{d}, \mathbf{k}$, I Uninucleate microspore stage. The degradation of the cytoplasm is evident in (k). e, $\mathbf{f}, \mathbf{m}-\mathbf{p}$ Bicellular stage. The degenerated microspore is shown in ( $\mathbf{m})$. Abnormal pollen wall patterning is visible in (o). $\mathbf{g}, \mathbf{h}, \mathbf{q}-\mathbf{t}$ Mature pollen stage. The mature pollen grain in (q) is devoid of any content and nuclei. The pollen wall structure in $(\mathbf{s}, \mathbf{t})$ is aberrant. $\mathbf{d}, \mathbf{f}, \mathbf{h}, \mathbf{l}, \mathbf{n}, \mathbf{p}, \mathbf{r}, \mathbf{t}$ Detailed structure of pollen walls in $(\mathbf{c}, \mathbf{e}, \mathbf{g}, \mathbf{k}, \mathbf{m}, \mathbf{o}, \mathbf{q}, \mathbf{s})$. Intine layers are absent in $(\mathbf{l}, \mathbf{n}, \mathbf{r})$. The abnormal thickening of intine layers in (p, $\mathbf{t}$ ) is obvious. Ba, baculum; Ex, exine; In, intine; Ne I, nexine I; Ne II, nexine II; Te, tectum; Tr, tryphine. Scale bars $=20 \mu \mathrm{m}(\mathbf{a}-\mathbf{c}, \mathbf{e}, \mathbf{g}, \mathbf{i}-\mathbf{k}, \mathbf{m}, \mathbf{0}, \mathbf{q}, \mathbf{s}) ; 0.5 \mu \mathrm{m}(\mathbf{d}, \mathbf{f}, \mathbf{h}, \mathbf{l}, \mathbf{n}, \mathbf{p}, \mathbf{r}, \mathbf{t})$ 


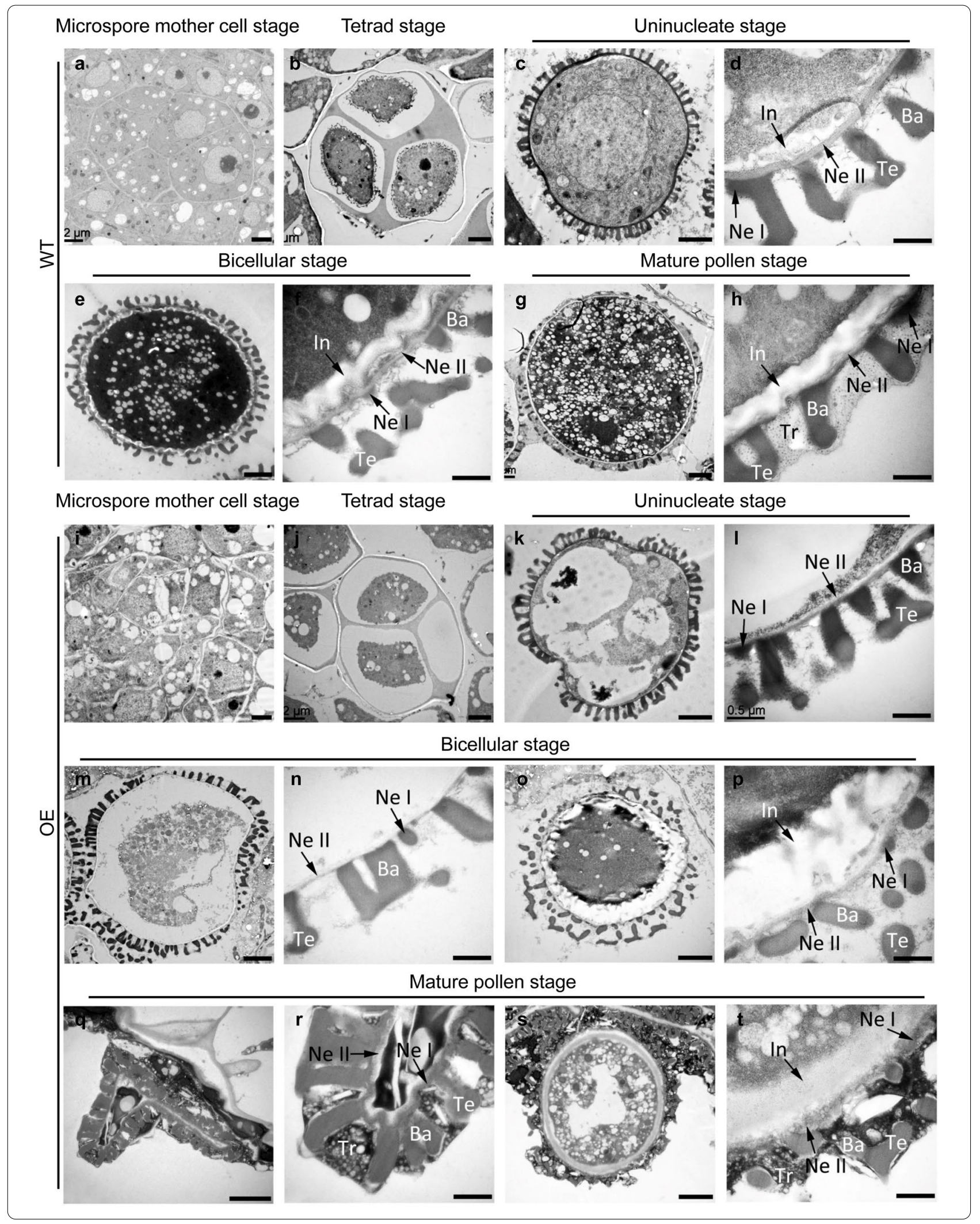




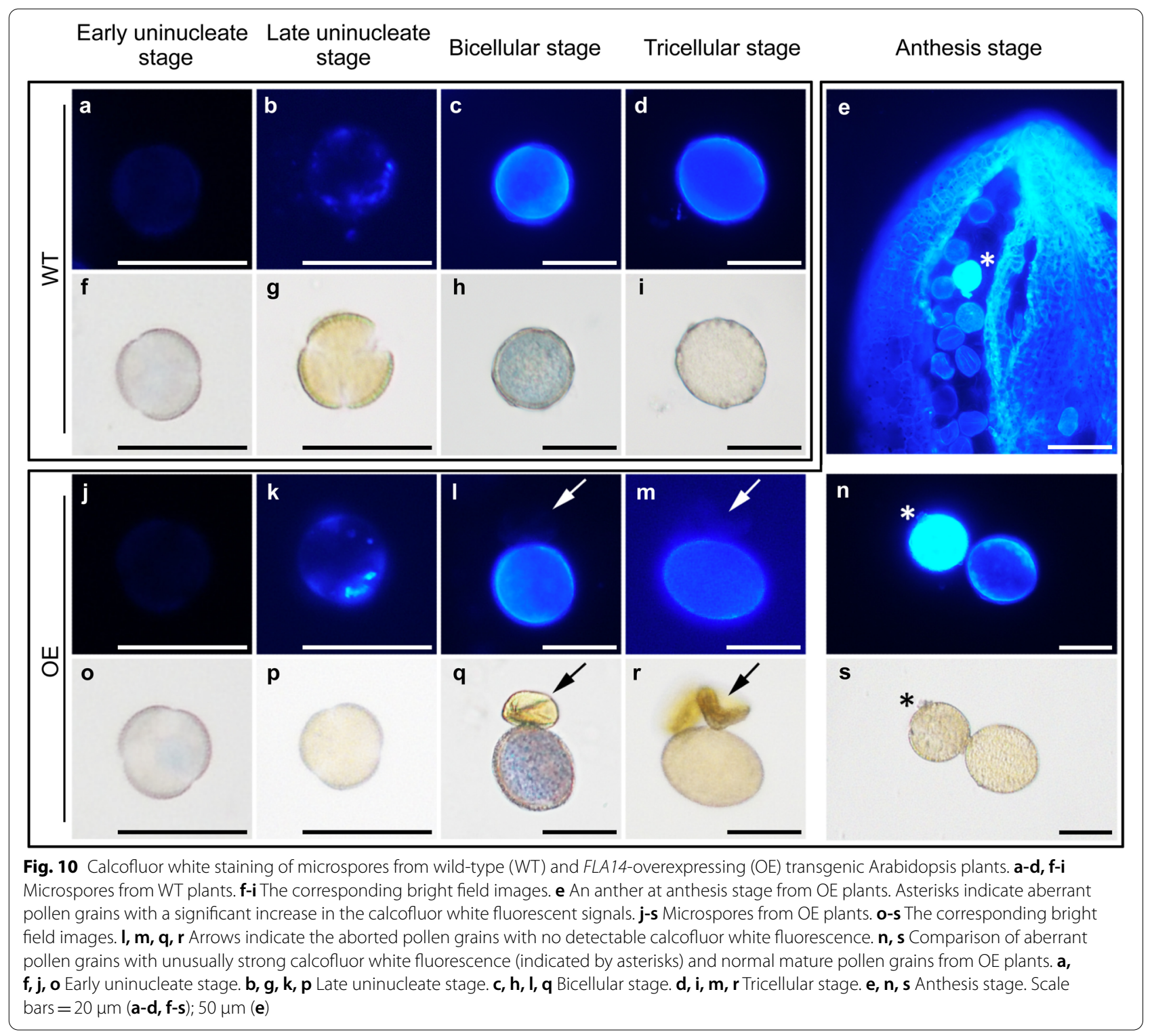

not only important for pollen development but also good candidates to mediate pollen tube growth. In addition, some specific members of AGPs were reported to be essential for preventing premature pollen grain germination. AGP6 and AGP11 are a pair of redundant AGPs involved in Arabidopsis pollen development and are necessary for proper pollen tube growth as well as for preventing premature germination of pollen grains inside anthers under high relative humidity [54]. AGP40 is an AG peptide that shows a high expression level in pollen grains and pollen tubes. Although AG peptides are very different molecules, typically consisting of fewer than 30 amino acid residues, AGP40 presents a high degree of similarity with and is closely related to AGP6 and AGP11. The single null mutant of AGP4O lacks obvious phenotypic differences when compared with WT plants however, a significantly higher number of early germinating pollen tubes inside the anthers were observed in agp6 agp11 agp40 triple mutants [20]. In our study, the results of preliminary characterization of the knockout mutant fla14 showed no alteration in microspore development, whereas high humidity affected the fla14 phenotype, resulting in a considerable number of precociously germinated pollen grains with over elongated pollen tubes inside mature anthers (Fig. 6). Precocious pollen germination was never observed in WT plants, even under 
conditions of high relative humidity. It is suggested that FLA14 is responsible for preventing premature pollen germination inside the anthers.

In previous studies, several mutants and overexpression transgenic plants with precocious pollen germination in anthers have been reported in Arabidopsis. The first known mutant with this novel defect, raring-to-go, showed precociously germinating pollen inside anthers in a humidity-dependent manner; unfortunately, the gene harboring this mutation has not been identified to date [55]. Arabidopsis plantacyanin overexpression resulted in defects in anther dehiscence, leading to a low level of precociously germinated pollen grains inside the closed anthers. A hypothesis was proposed that pollen may interpret the presence of plantacyanin in mature anthers as a stigmatic signal and hence respond by germinating [56]. In addition, a loss-of-function mutant callose synthase 9 and a transgenic plant overexpressing Callose Synthase 5 both contain abnormal callose deposition during microsporogenesis and show precocious pollen germination [57]. Studies of these well-characterized mutants or overexpression plants in Arabidopsis demonstrate that precocious pollen germination could be triggered by a genetic alteration. However, unlike pollen grains from these mutants or overexpression lines, which do germinate under normal culture conditions, the premature germination of pollen grains in the anthers from fla14 and agp 6 agp 11 is dependent on high humidity.

Normally, pollen tube germination and directional growth occur after anthesis, and premature germination inside anthers does not occur [54]. To date, dehydration is considered to be the main factor in maintaining pollen dormancy and preventing precocious germination [58]. Pollen adhesion and rehydration break dormancy and are postulated to be the initial steps for triggering pollen germination [59]. However, the underlying mechanisms of these events are still poorly understood. It has been reported that mutations in OsOSC12/OsPTS1, encoding a bicyclic triterpene synthase, resulted in defective pollen adhesion and hydration in rice under low-humidity conditions [60]. High humidity can rescue the defective pollen hydration resulting from loss-of-function mutants of OsGL1-4, a member of the Glossy family in rice [61]. Altered environmental humidity caused precocious pollen germination in inositol polyphosphate 5-phosphatase 12 mutants [58]. Pollen deficient in the NMNAT gene, encoding a key enzyme in NAD biosynthesis, often precociously germinates in the locule under high-humidity conditions [62]. All these findings indicate that hydration/humidity is essential for pollen germination and that various components affecting pollen adhesion and hydration in response to environmental humidity are also required. An interesting phenotype, precocious pollen germination within fla14 (Fig. 6) and agp6 agp11 anthers [54], indicated that accumulation of AGPs during pollen maturation is important to repress pollen tube germination under high-humidity conditions.

In male-female cross-talk during pollen germination, the pollen grain has to hydrate, and the stigma serves as a source of water and other factors. Concurrently, the pollen coat must provide lipids and proteins required for this crucial hydration step [54]. Microscopic observations of fla14 showed no defects in female organ function (Fig. 7). Moreover, mutation of FLA14 did not seem to produce any conspicuous effect on the deposition of the pollen coat material according to the TEM observations of mutant pollen grains (Fig. 9). All these results indicated that pollen contact with the stigma may not be compromised in the mutant plants. It has been suggested that AGPs are involved in the control of pollen germination possibly by a relatively simple process of modulating access to water for hydration or by interfering with some kind of signaling pathway [23]. Therefore, the early germinating pollen tubes inside the fla14 anther may be attributed to the early uptake of water or other factors.

It has been reported that during pollen germination, pollen is first activated by the uptake of water and calcium ions $\left(\mathrm{Ca}^{2+}\right)$ into the pollen grain, and then a cytoplasmic gradient of $\mathrm{Ca}^{2+}$ forms beneath the site of germination [63]. In accordance with this, the expression levels of calcium- and signaling-related genes were found to be altered in double null mutant agp 6 agp11 pollen tubes, indicating the putative involvement of AGPs in signaling cascades through calmodulin [64]. Further investigation confirmed that AGPs can bind $\mathrm{Ca}^{2+}$, which is released in specific stages of pollen germination and tube elongation, to form an AGP-Ca ${ }^{2+}$ oscillator $[65,66]$. Moreover, the properties of AGPs combined with Hechtian strand-mediated adhesion offer a solution based on a Hechtian oscillator that dissociates periplasmic AGP-Ca ${ }^{2+}$, resulting in $\mathrm{Ca}^{2+}$ influx [67]. The Hechtian hypothesis proposes that AGP functions as a $\mathrm{Ca}^{2+}$ capacitor and pollen tube guide that regulates pollen tip growth [67]. Subcellular localization of FLA14 showed that FLA14 was distributed on the plasma membrane and in Hechtian strands (Fig. 2). This result is consistent with the presence of a putative GPI anchor signal sequence predicted from the gene (Additional file 2: Fig. S2). Hechtian strands in the adhesion zones connect the cell wall to the plasma membrane, mechanically transduce cell wall stress signals to receptors located in the plasma membrane and are suggested to be implicated in signal transduction, cell-cell communication events and sensing cell wall integrity [68, 69]. Several members of the AGP family, such as LeAGP1 in tomato and FLA4, AtAGP17 and AtAGP18 in Arabidopsis, have been found to be distributed on the plasma membrane and in Hechtian strands and are proposed to be a kind of 
medium connecting the plasma membrane and cell wall $[14,68,70-73]$. The plasma membrane and Hechtian strand localization of FLA14 was implied to mediate its function in cell adhesion and signaling during pollen germination [36]. It has been hypothesized that external dynamic storage by a periplasmic AGP flux capacitor may be associated with the adaptation of the cell to changing conditions and its response to stress factors [27, 66, 67]. Based on this hypothesis, we speculate that interference of the plasma membrane and Hechtian strand-localized FLA14 might disturb the sensing of external signals and disrupt periplasmic AGP$\mathrm{Ca}^{2+}$ dissociation, as well as destabilize networks in pollen grains and pollen tubes, causing failure in the pollen tube response to high humidity and prevention of premature pollen germination inside the anthers. It would be interesting to investigate whether the fla14 mutant may have any defect in the expression of calcium- and signaling-related genes that are critical for pollen germination and tube growth.

\section{Conclusions}

In this study, we characterized an Arabidopsis FLA member, FLA14, a pollen-specific protein localized at the plasma membrane and in Hechtian strands. In addition, we demonstrated a role for FLA14 in male gametophyte development and pollen germination inside the anthers under high relative humidity. These findings provide novel insights into the implications of AGPs in plant reproductive development.

\section{Methods}

\section{Plant materials and growth conditions}

An ecotype of Arabidopsis with a Columbia-0 background, as well as T-DNA mutant and transgenic plants, were cultivated in potting mix in a $22 \pm 2{ }^{\circ} \mathrm{C}$ growth cabinet with $50 \%$ relative humidity and a 16 -h light and 8 -h dark cycle.

\section{Phylogenetic analysis and expression analysis of FLA genes in Arabidopsis}

The 21 FLA protein sequences were obtained from the TAIR (https://www.arabidopsis.org/) database. Multiple alignments of amino acid sequences were performed using the Clustal X (version 1.83) program. A phylogenetic tree was constructed in MEGA X software with the neighbor-joining algorithm method. The bootstrap value was 1000 . The generated.nwk file was then used as the input to construct the final phylogenetic tree using the OmicStudio tools at https://www.omicstudio.cn/tool/.

The gene expression data for all 21 FLAs were obtained from the AtGenExpress Consortium (Arabidopsis eFP Browser, available at http://www.bar.utoronto.ca/) in ATH1 and Klepikova data sources and previously published articles [37, 38, 74, 75]. A hierarchical clustering heatmap was produced to visualize the gene expression level using the OmicStudio tools at https://www. omicstudio.cn/tool/.

\section{Bioinformatic analysis}

The amino acid composition of FLA14 was computed using the ProtParam tool (http://web.expasy.org/protp aram/). Pairwise sequences were compared by the Align tool (http://www.ebi.ac.uk/). The SignalP 4.0 Server (http://www.cbs.dtu.dk/services/SignalP-4.0/), the TMHMM Server v. 2.0 (http://www.cbs.dtu.dk/services/ TMHMM/), and SMART (http://smart.embl-heidelberg. de) were used to determine the predicted length of the $\mathrm{N}$-terminal signal sequence of FLA14. Original prediction for the GPI modification site was performed using GPI-SOM (http://gpi.unibe.ch) and BIG-PI Plant Predictor (http://mendel.imp.ac.at/gpi/plant_server.html). The cis-acting elements in the FLA14 promoter sequence were identified using the PlantCare (http://bioinformatics. psb.ugent.be/webtools/plantcare/html). WoLF PSORT (http://wolfpsort.org/) was used to determine protein subcellular localization. Other information on FLA14 was obtained from NCBI (http://www.ncbi.nlm.nih.gov).

\section{RNA extraction, cDNA synthesis and quantitative real-time PCR}

Total RNA was extracted using Trizol ${ }^{\circledR}$ reagent (Invitrogen, http://www.lifetechnologies.com) and transcribed into cDNA with a PrimeScript ${ }^{\circledR}$ RT Reagent Kit with gDNA Eraser (TaKaRa, http://www.takarabiomed.com. $\mathrm{cn})$. Then, the CDNA was used as the template for PCR analysis with specific primers (Additional file 4: Table S1). Tubulin beta-4 (Tub4) was used as the normalization control [52]. Quantitative real-time PCR was performed in a mixture containing SYBR ${ }^{\circledR}$ Premix Ex TaqTM (TliRNaseH Plus) (TaKaRa, http://www.takarabiomed.com.cn) on a BioRad CFX96 Real-time RT-PCR Detection System (Bio-Rad, http://www.bio-rad.com). Three technical repeats and three biological replicates were performed. The values represent the means \pm SD (standard deviation) of three biological replicates. The relative expression levels were calculated by the $2^{-\triangle \triangle \mathrm{Ct}}$ method [76].

\section{GUS staining analysis and GFP fluorescence microscopy}

For analysis of FLA14 promoter activity, we first constructed a $p B 1101-e G F P-G U S$ empty vector as follows: the enhanced green fluorescent protein (eGFP) gene coding ORF fragment with the modified stop codon was PCR-amplified using specific primers and cloned into plasmid pBI101 at the SmaI recognition site upstream of the $\beta$-glucuronidase (GUS) gene. 
The proFLA14::eGFP-GUS construct was generated by amplifying the FLA14 promoter sequence $2074 \mathrm{bp}$ upstream from the first ATG of the FLA14 coding ORF fragment using gene-specific primers. The fragment was inserted upstream of the $e G F P$ gene at the $B a m H I$ recognition site in the pBI101 plasmid, which contained the NPTII kanamycin resistance gene. All primers are listed in Additional file 4: Table S1. Homozygous transgenic plants were used for GUS staining with 5 -bromo-4-chloro-3-indolyl- $\beta$-glucuronic acid and GFP observation. Images of GUS-stained and GFPexpressing tissues were collected using a fluorescence microscope (ECLIPSE 90i; Nikon).

\section{Subcellular localization}

To observe FLA14 subcellular distribution, we amplified the FLA14 signal peptide sequence and the rest of the FLA14 ORF fragment. Then, these two sequences were subcloned into the 3'- and 5'-termini of GFP in the $p F G C$-eGFP vector under the control of the constitutive CaMV 35S promoter to avoid disturbing the potential function of the signal peptide, resulting in the modified vector $p F G C-N S^{F L A 14}-e G F P-F L A 14$. All primers are listed in Additional file 4: Table S1. The modified vector was then transiently transformed into onion epidermal cells by particle bombardment [77]. The onion epidermal layer was peeled $24 \mathrm{~h}$ after introduction and plasmolyzed in $0.3 \mathrm{~g} \cdot \mathrm{mL}^{-1}$ sucrose for $3 \mathrm{~min}$. The expression of eGFPfusion protein was analyzed with a fluorescence microscope (ECLIPSE 90i; Nikon) and an LSM780 confocal microscope (ZEISS, Germany).

\section{Mutant verification}

Mutant seeds of two lines, CS1014037 and SALK_123695, were obtained from the Arabidopsis Biological Resource Center (http://www.biosci.ohio-state.edu/pcmb/Facilities/ abrc/abrchome.htm). Genomic DNA was isolated from fresh young leaves using the cetyl trimethyl ammonium bromide extraction method [78]. Homozygous lines were screened by PCR with FLA14-specific primers (Additional file 4: Table S1) and T-DNA primer (5'TTCTCATCTAAGCCCCCA TTTGG-3'). The PCR products were confirmed by sequencing. Total RNA from homozygous mutants was extracted, and quantitative real-time PCR was performed to analyze the expression of FLA14 according to the method described above with three specific primer pairs (Additional file 4: Table S1).

\section{Construction of FLA14-overexpressing recombinant plasmid and plant transformation}

For the overexpression construct, the ORF of FLA14 was amplified and subcloned into the pBI121 vector under the control of the constitutive CaMV 35S promoter at the XbaI and SmaI recognition sites, which flanked the NPTII kanamycin resistance gene. After sequencing, the recombinant construct was transformed into Arabidopsis using the floral dip method [79]. $\mathrm{T}_{2}$ generation plants were used for further experiments after verification. All primers used are listed in Additional file 4: Table S1.

\section{Light microscopy}

A week after the first anthesis, florets were collected and observed with a Leica MZ16FA stereoscopic microscope (http://www.leica.com/). Siliques were fixed with 1:9 acetic acid/ethanol overnight at $4{ }^{\circ} \mathrm{C}$, transferred to $90 \%$ ethanol for $1 \mathrm{~h}$ at room temperature, and left in $70 \%$ ethanol overnight at $4{ }^{\circ} \mathrm{C}$ [80]. Ethanol-fixed siliques were visualized under a Leica MZ16FA stereoscopic microscope (http://www.leica.com/).

For cytological analysis, 4,6-diamidino-1-phenylindole (DAPI) solution was used to detect the nuclei of pollen grains [81]. Pollen viability was observed by staining with Alexander stain [82]. To observe the callose wall, pollen grains were labeled with $0.1 \%(\mathrm{w} / \mathrm{v})$ aniline blue in $0.1 \mathrm{M} \mathrm{K}_{2} \mathrm{HPO}_{4}-\mathrm{KOH}$ buffer ( $\mathrm{pH} 11$ ) according to the manufacturer's instructions (Roche, Germany). To trace the deposition of cellulose-like polysaccharides in the pollen wall, anthers and pollen grains were fixed in 5\% $(\mathrm{v} / \mathrm{v})$ formalin and $5 \%(\mathrm{v} / \mathrm{v})$ glacial acetic acid in ethanol overnight and then stained in calcofluor white for $5 \mathrm{~min}$ [83]. The stained specimens were observed with a Leica DMLB fluorescence microscope (http://www.leica. $\mathrm{com} /$ ).

For semithin section analyses, floral buds were fixed and prepared as described by Lin et al. [50]. After embedding in spurr resin, semithin sections $(1 \mu \mathrm{m})$ were obtained under an LKB 11800 PYRAMITOME ultramicrotome (Stockholm, Sweden), placed on glass slides, stained with $0.5 \%$ toluidine blue, and photographed by a Leica DMLB fluorescence microscope (http://www.leica. $\mathrm{com} /$ ).

\section{Electron microscopy}

For scanning electron microscopy (SEM), anthers at the anthesis stage and mature pollen grains were spread, coated with gold-palladium in an Eiko Model ion coater (Ibaraki, Japan) for $5 \mathrm{~min}$, and then observed in a Hitachi Model TM-1000 SEM (Tokyo, Japan). For transmission electron microscopy (TEM), anthers were fixed and embedded as described above. Ultrathin sections $(70 \mathrm{~nm})$ were obtained using an ultramicrotome (Reichert-Jung Ultracut E, Vienna, Austria) and stained with uranyl acetate and alkaline lead citrate for $15 \mathrm{~min}$. Images were recorded with a Hitachi Model H-7650 TEM (Tokyo, Japan). 


\section{Pollen germination assays}

For pollen germination assays, three-week-old Arabidopsis plantlets were grown under controlled conditions at $50 \%$ relative humidity, while another subset of plants was transferred to a growth cabinet set at $85 \%$ relative humidity. The anthers were collected 3 days after high humidity treatment and subjected to microscopy observation as described above.

\section{Self and reciprocal crosses}

For self and reciprocal crosses, florets were pre-emasculated and pollinated 2 days before anthesis. Pistils were excised 4, 12, and $24 \mathrm{~h}$ after pollination, fixed in Carnoy's solution (ethanol:alcohol acetic $=3: 1$ ) for $2 \mathrm{~h}$, washed three times with water, softened with $8 \mathrm{M}$ $\mathrm{NaOH}$ overnight, washed three additional times with water, and incubated for $3 \mathrm{~h}$ in $0.1 \%(\mathrm{w} / \mathrm{v})$ aniline blue in $0.1 \mathrm{M} \mathrm{K}_{2} \mathrm{HPO}_{4}-\mathrm{KOH}$ buffer ( $\left.\mathrm{pH} 11\right)$. Three replicates were performed for each crossing. The specimens were observed with a Leica MZ16FA stereoscopic microscope (http://www.leica.com/).

\begin{abstract}
Abbreviations
AGP: Arabinogalactan protein; $\mathrm{Ca}^{2+}$ : Calcium ions; DAPI: 4,6-Diamidino1-phenylindole; eGFP: Enhanced green fluorescent protein; FAS: Fasciclin; FLA: Fasciclin-like AGP; GPI: Glycosyl phosphatidylinositol; GUS: $\beta$-Glucoronidase; OE: Over-expression; ORF: Open reading frame; SEM: Scanning electron microscopy; SD: Standard deviation; TEM: Transmission electron microscopy; Tub4: Tubulin beta-4; WT: Wild-type.
\end{abstract}

\section{Supplementary Information}

The online version contains supplementary material available at https://doi. org/10.1186/s12870-021-03038-x.

\section{Additional file 1:}

Additional file 2:

Additional file 3:

Additional file 4:

Additional file 5:

\section{Acknowledgements}

Not applicable.

\section{Authors' contributions}

JC and SL conceived and designed the research. YM, LH and YY performed the experiments. YM and SL analyzed the data and wrote the manuscript. All authors read and approved the final manuscript.

\section{Funding}

This work was supported by the National Natural Science Foundation of China [31972418, 31501764 and 31572126].

\section{Availability of data and materials}

The datasets used and/or analysed during the current study available from the corresponding author on reasonable request.

\section{Declarations}

Ethics approval and consent to participate

Not applicable.

\section{Consent for publication}

Not applicable.

\section{Competing interests}

The authors declare that they have no competing interests.

\section{Author details}

${ }^{1}$ Institute of Life Sciences, College of Life and Environmental Science, Wenzhou University, Wenzhou 325000, China. ${ }^{2}$ Laboratory of Cell \& Molecular Biology, Institute of Vegetable Science, Zhejiang University, Hangzhou 310058, China. ${ }^{3}$ College of Agriculture and Food Science, Zhejiang A \& F University, Lin'an 311300, China. ${ }^{4}$ Biomedical Collaborative Innovation Center of Zhejiang Province, Wenzhou 325000, China.

Received: 28 December 2020 Accepted: 11 May 2021

Published online: 03 June 2021

\section{References}

1. Twell D. Male gametophyte development. In: Pua EC, Davey MR, editors. Plant Developmental Biology-Biotechnological Perspectives. Berlin: Springer-Verlag; 2010. p. 225-44

2. Hafidh S, Fíla J, Honys D. Male gametophyte development and function in angiosperms: a general concept. Plant Reprod. 2016;29:31-51.

3. Rutley N, Twell D. A decade of pollen transcriptomics. Plant Reprod. 2015;28:73-89.

4. Dong X, Kim WK, Lim YP, Kim YK, Hur Y. Ogura-CMS in Chinese cabbage (Brassica rapa ssp. pekinensis) causes delayed expression of many nuclear genes. Plant Sci. 2013;199:7-17.

5. Ariizumi T, Toriyama K. Genetic regulation of sporopollenin synthesis and pollen exine development. Annu Rev Plant Biol. 2011;62:1.1-1.24.

6. Wilson ZA, Zhang DB. From Arabidopsis to rice: pathways in pollen development. J Exp Bot. 2009;60:1479-92.

7. Lou Y, Zhu J, Yang Z. Molecular cell biology of pollen walls. In: Nick P, Opatrný Z, editors. Applied Plant Cell Biology. Berlin, Heidelberg: Springer-Verlag; 2014. p. 179-205.

8. Kapoor S, Kobayashi A, Takatsuji H. Silencing of the tapetum-specific zinc finger gene TAZ1 causes premature degeneration of tapetum and pollen abortion in petunia. Plant Cell. 2002;14:2353-67.

9. Dresselhaus T, Franklin-Tong N. Male-female crosstalk during pollen germination, tube growth and guidance, and double fertilization. Mol Plant. 2013;6:1018-36.

10. Honys D, Reňák D, Twell D. Male gametyphyte development and function. In: da Silva JT, editor. Floriculture, ornamental and plant biotechnology: advances and topical issues. 1st ed. London: Global Science Books; 2006. p. 76-87.

11. Becker JD, Feijo JA. How many genes are needed to make a pollen tube? Lessons from transcriptomics Ann Bot. 2007:100:1117-23.

12. Shi J, Cui M, Yang L, Kim YJ, Zhang D. Genetic and biochemical mechanisms of pollen wall development. Trends Plant Sci. 2015;20:741-53.

13. Showalter AM. Arabinogalactan-proteins: structure, expression and function. Cell Mol Life Sci. 2001:58:1399-417.

14. Seifert GJ, Roberts K. The biology of arabinogalactan proteins. Annu Rev Plant Biol. 2007;58:137-61.

15. Ellis M, Egelund J, Schultz CJ, Bacic A. Arabinogalactan-proteins: key regulators at the cell surface? Plant Physiol. 2010;153:403-19. 
16. Showalter AM, Keppler BD, Lichtenberg J, Gu D, Welch LR. A bioinformatics approach to the identification, classification, and analysis of hydroxyproline-rich glycoproteins. Plant Physiol. 2010;153:485-513.

17. Ma T, Dong F, Luan D, Hu H, Zhao J. Gene expression and localization of arabinogalactan proteins during the development of anther, ovule, and embryo in rice. Protoplasma. 2019;256:909-22.

18. Majewska-Sawka A, Nothnagel EA. The multiple roles of arabinogalactan proteins in plant development. Plant Physiol. 2000;122:3-9.

19. Rumyantseva NI. Arabinogalactan proteins: involvement in plant growth and morphogenesis. Biochemistry-Moscow+. 2005;70:1073-85.

20. Nguema-Ona E, Coimbra S, Vicré-Gibouin M, Mollet JC, Driouich A. Arabinogalactan proteins in root and pollen-tube cells: distribution and functional aspects. Ann Bot. 2012;110:383-404.

21. Nguema-Ona E, Vicré-Gibouin M, Cannesan MA, Driouich A. Arabinogalactan proteins in root-microbe interactions. Trends Plant Sci. 2013;18:440-9.

22. $\mathrm{Ma} \mathrm{HL}$, Yu L, Liang RH, Zhao J. Functional studies of arabinogalactan proteins in higher plants. SCIENTIA SINICA Vitae. 2015:45:113-23.

23. Pereira AM, Pereira LG, Coimbra S. Arabinogalactan proteins: rising attention from plant biologists. Plant Reprod. 2015;28:1-15.

24. Pereira AM, Lopes AL, Coimbra S. Arabinogalactan proteins as interactors along the crosstalk between the pollen tube and the female tissues. Front Plant Sci. 2016;7:1895.

25. Su S, Higashiyama T. Arabinogalactan proteins and their sugar chains: functions in plant reproduction, research methods, and biosynthesis. Plant Reprod. 2018;31:67-75.

26. Mareri L, Romi M, Cai G. Arabinogalactan proteins: actors or spectators during abiotic and biotic stress in plants? Plant Biosystems-An International Journal Dealing with all Aspects of Plant Biology. 2019;153:173-85

27. Leszczuk A, Szczuka E, Zdunek A. Arabinogalactan proteins: Distribution during the development of male and female gametophytes. Plant Physiol Bioch. 2019;135:9-18.

28. Schultz CJ, Rumsewicz MP, Johnson KL, Jones BJ, Gaspar YM, Bacic A. Using genomic resources to guide research directions. The arabinogalactan protein gene family as a test case. Plant Physiol. 2002;129:1448-63.

29. Kim J, Kim S, Lee B, Choi J, Park R, Park J, et al. Identification of motifs in the fasciclin domains of the transforming growth factor- $\beta$-induced matrix protein $\beta i g-h 3$ that interact with the $a v \beta 5$ integrin. J Biol Chem. 2002;277:46159-65

30. Johnson KL, Jones BJ, Bacic A, Schultz CJ. The fasciclin-like arabinogalactan proteins of Arabidopsis. A multigene family of putative cell adhesion molecules. Plant Physiol. 2003;133:1911-25.

31. Faik A, Abouzouhair J, Sarhan F. Putative fasciclin-like arabinogalactanproteins (FLA) in wheat (Triticum aestivum) and rice (Oryza sativa): identification and bioinformatic analyses. Mol Genet Genomics. 2006;276:478-94

32. Zang $L$, Zheng T, Su X. Advances in research of fasciclin-like arabinogalactan proteins (FLAs) in plants. Plant Omics. 2015;8:190-4.

33. He J, Zhao H, Cheng Z, Ke Y, Liu J, Ma H. Evolution analysis of the fasciclinlike arabinogalactan proteins in plants shows variable fasciclin-AGP domain constitutions. IJMS. 2019;20:1945.

34. Ma H, Zhao J. Genome-wide identification, classification, and expression analysis of the arabinogalactan protein gene family in rice (Oryza sativa L.). J Exp Bot. 2010;61:2647-68.

35. Li J, Yu M, Geng LL, Zhao J. The fasciclin-like arabinogalactan protein gene, FLA3, is involved in microspore development of Arabidopsis. Plant J. 2010;64:482-97.

36. Tan $\mathrm{H}$, Liang W, Hu J, Zhang D. MTR1 encodes a secretory fasciclin glycoprotein required for male reproductive development in rice. Dev Cell. 2012;22:1127-37.

37. Honys D, Twell D. Transcriptome analysis of haploid male gametophyte development in Arabidopsis. Genome Biol. 2004;5:R85.

38. Loraine AE, McCormick S, Estrada A, Patel K, Qin P. RNA-Seq of Arabidopsis pollen uncovers novel transcription and alternative splicing. Plant Physiol. 2013;162:1092-109.

39. Smyth DR, Bowman JL, Meyerowitz EM. Early flower development in Arabisopsis. Plant Cell. 1990;2:755-67.
40. Park BS, Kim JS, Kim SH, Park YD. Characterization of a pollen-preferential gene, BAN102, from Chinese cabbage. Plant Cell Rep. 2005;24:663-70.

41. Coimbra S, Costa M, Jones B, Mendes MA, Pereira LG. Pollen grain development is compromised in Arabidopsis agp6 agp 11 null mutants. J Exp Bot. 2009;60:3133-42

42. Lin S, Yue X, Miao Y, Yu Y, Dong H, Huang L, et al. The distinct functions of two classical arabinogalactan proteins BCMF8 and BCMF18 during pollen wall development in Brassica campestris. Plant J. 2018;94:60-76.

43. Levitin B, Richter D, Markovich I, Zik M. Arabinogalactan proteins 6 and 11 are required for stamen and pollen function in Arabidopsis. Plant J. 2008;56:351-63.

44. Lin S, Dong H, Zhang F, Qiu L, Wang F, Cao J, et al. BCMF8, a putative arabinogalactan protein-encoding gene, contributes to pollen wall development, aperture formation and pollen tube growth in Brassica campestris. Ann Bot-London. 2014;113:777-88.

45. Schnurr JA, Storey KK, Jung HJG, Somers DA, Gronwald JW. UDP-sugar pyrophosphorylase is essential for pollen development in Arabidopsis. Planta. 2006;224:520-32.

46. Knorre DG, Kudryashova NV, Godovikova TS. Chemical and functional aspects of posttranslational modification of proteins. Acta Naturae. 2009;1:29-51.

47. Lamport DTA, Kieliszewski MJ, Showalter AM. Salt stress upregulates periplasmic arabinogalactan proteins: using salt stress to analyse AGP function. New Phytol. 2006;169:479-92.

48. Hijazi M, Velasquez SM, Jamet E, Estevez JM, Albenne C. An update on post-translational modifications of hydroxyproline-rich glycoproteins: toward a model highlighting their contribution to plant cell wall architecture. Front Plant Sci. 2014:5:395.

49. Tan L, Eberhard S, Pattathil S, Warder C, Glushka J, Yuan C, et al. An Arabidopsis cell wall proteoglycan consists of pectin and arabinoxylan covalently linked to an arabinogalactan protein. Plant Cell. 2013;25:270-87.

50. Lin S, Huang L, Miao Y, Yu Y, Peng R, Cao J. Constitutive overexpression of the classical arabinogalactan protein gene BCMF18 in Arabidopsis causes defects in pollen intine morphogenesis. Plant Growth Regul. 2019;88:159-71.

51. Hesse M. Pollen wall stratification and pollination. Plant Syst Evol. 2000:222:1-17.

52. Pereira LG, Coimbra S, Oliveira H, Monteiro L, Sottomayor M. Expression of arabinogalactan protein genes in pollen tubes of Arabidopsis thaliana. Planta. 2006;223:374-80.

53. Qin $Y$, Chen $D$, Zhao J. Localization of arabinogalactan proteins in anther, pollen, and pollen tube of Nicotiana tabacum L. Protoplasma. 2007;231:43-53.

54. Coimbra S, Costa M, Mendes MA, Pereira AM, Pinto J, Pereira LG. Early germination of Arabidopsis pollen in a double null mutant for the arabinogalactan protein genes AGP6 and AGP11. Sex Plant Reprod. 2010:23:199-205.

55. Johnson SA, McCormick S. Pollen germinates precociously in the anthers of raring-to-go, an Arabidopsis gametophytic mutant. Plant Physiol. 2001;126:685-95.

56. Dong J, Kim ST, Lord EM. Plantacyanin plays a role in reproduction in Arabidopsis. Plant Physiol. 2005;138:778-89.

57. Xie $B$, Wang $X$, Hong Z. Precocious pollen germination in Arabidopsis plants with altered callose deposition during microsporogenesis. Planta. 2010;231:809-23.

58. Wang Y, Chu YJ, Xue HW. Inositol polyphosphate 5-phosphatase-controlled Ins $(1,4,5) P 3 / \mathrm{Ca} 2+$ is crucial for maintaining pollen dormancy and regulating early germination of pollen. Development. 139:2221-33.

59. Shi DQ, Yang WC. Pollen germination and tube growth. In: Pua EC, Davey MR, editors. Plant Developmental Biology-Biotechnological Perspectives. Berlin: Springer-Verlag; 2010. p. 245-82.

60. Xue Z, Xu X, Zhou Y, Wang X, Zhang Y, Liu D, et al. Deficiency of a triterpene pathway results in humidity-sensitive genic male sterility in rice. Nat Commun. 2018;9:604.

61. Yu B, Liu L, Wang T. Deficiency of very long chain alkanes biosynthesis causes humidity-sensitive male sterility via affecting pollen adhesion and hydration in rice. Plant Cell Environ. 2019:42:3340-54.

62. Hashida S, Takahashi H, Takahara K, Kawai-Yamada M, Kitazaki K, Shoji $\mathrm{K}$, et al. NAD+ accumulation during pollen maturation in Arabidopsis regulating onset of germination. Mol Plant. 2013;6:216-25. 
63. Heslop-Harrison J, Heslop-Harrison Y. Germination of monocolpate angiosperm pollen: effects of inhibitory factors and the Ca2+-channel blocker, nifedipine. Ann Bot. 1992;69:395-403.

64. Costa M, Nobre MS, Becker JD, Masiero S, Amorim MI, Pereira LG, et al. Expression-based and co-localization detection of arabinogalactan protein 6 and arabinogalactan protein 11 interactors in Arabidopsis pollen and pollen tubes. BMC Plant Biol. 2013;13:7.

65. Lamport DTA, Várnai P. Periplasmic arabinogalactan glycoproteins act as a calcium capacitor that regulates plant growth and development. New Phytol. 2013;197:58-64.

66. Lamport DTA, Varnai P, Seal CE. Back to the future with the AGP-Ca2+ flux capacitor. Ann Bot. 2014;114:1069-85.

67. Lamport DTA, Tan L, Held MA, Kieliszewski MJ. Pollen tube growth and guidance: Occam's razor sharpened on a molecular arabinogalactan glycoprotein Rosetta Stone. New Phytol. 2018;217:491-500.

68. Sardar HS, Yang J, Showalter AM. Molecular interactions of arabinogalactan proteins with cortical microtubules and F-actin in Bright Yellow-2 tobacco cultured cells. Plant Physiol. 2006;142:1469-79.

69. Yoneda A, Ohtani M, Katagiri D, Hosokawa Y, Demura T. Hechtian strands transmit cell wall integrity signals in plant cells. Plants. 2020;9:604

70. Sun W, Zhao ZD, Hare MC, Kieliszewski MJ, Showalter AM. Tomato LeAGP-1 is a plasma membrane-bound, glycosylphosphatidylinositolanchored arabinogalactan-protein. Physiol Plant. 2004;120:319-27.

71. Xue H, Veit C, Abas L, Tryfona T, Maresch D, Ricardi MM, et al. Arabidopsis thaliana FLA4 functions as a glycan-stabilized soluble factor via its carboxy-proximal Fasciclin 1 domain. Plant J. 2017;91:613-30.

72. Sun W, Xu J, Yang J, Kieliszewski MJ, Showalter AM. The Lysine-rich arabinogalactan-protein subfamily in Arabidopsis: gene expression, glycoprotein purification and biochemical characterization. Plant Cell Physiol. 2005;46:975-84.

73. Yang J, Showalter AM. Expression and localization of AtAGP18, a lysinerich arabinogalactan-protein in Arabidopsis. Planta. 2007;226:169-79.

74. Winter D, Vinegar B, Nahal H, Ammar R, Wilson GV, Provart NJ. An "electronic Fluorescent Pictograph" Browser for exploring and analyzing large-scale biological data sets. PLoS ONE. 2007;2:e718.
75. Klepikova AV, Kasianov AS, Gerasimov ES, Logacheva MD, Penin AA. A high resolution map of the Arabidopsis thaliana developmental transcriptome based on RNA-seq profiling. Plant J. 2016;88:1058-70.

76. Livak KJ, Schmittgen TD. Analysis of relative gene expression data using real-time quantitative PCR and the 2(-Delta Delta C(T)) method. Methods. 2001;25:402-8

77. Gan C. Gene gun accelerates DNA-coated particles to transform intact cells. Scientist. 1989;3:25.

78. McDonald BA, Martinez JP. Restriction fragment length polymorphisms in Septoria tritici occur at a high frequency. Curr Genet. 1990;17:133-8.

79. Zhang X, Henriques R, Lin SS, Niu QW, Chua NH. Agrobacterium-mediated transformation of Arabidopsis thaliana using the floral dip method. Nat Protoc. 2006;1:641-6.

80. Pereira AM, Nobre MS, Pinto SC, Lopes AL, Costa ML, Masiero S, et al. "Love is strong, and you're so sweet": JAGGER is essential for persistent synergid degeneration and polytubey block in Arabidopsis thaliana. Mol Plant. 2016;9:601-14

81. Regan SM, Moffatt BA. Cytochemical analysis of pollen development in wild-type Arabidopsis and a male-sterile mutant. Plant Cell. 1990:2:877-89.

82. Alexander MP. Differential staining of aborted and non-aborted pollen. Stain Technol. 1969;44:117-22.

83. Mohebali M, Mirbakhsh M, Keshavarz H. Rapid detection of Pneumocystis Carini in spiratory specimens of rats by calcofluor white staining. Iran J Public Health. 2002:31:108-10.

\section{Publisher's Note}

Springer Nature remains neutral with regard to jurisdictional claims in published maps and institutional affiliations.
Ready to submit your research? Choose BMC and benefit from:

- fast, convenient online submission

- thorough peer review by experienced researchers in your field

- rapid publication on acceptance

- support for research data, including large and complex data types

- gold Open Access which fosters wider collaboration and increased citations

- maximum visibility for your research: over $100 \mathrm{M}$ website views per year

At BMC, research is always in progress.

Learn more biomedcentral.com/submissions 